\title{
Thermoeconomic optimisation of small-scale organic Rankine cycle systems based on screw vs. piston expander maps in waste heat recovery applications
}

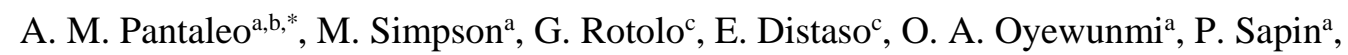
P. De Palma ${ }^{\mathrm{c}}$, C. N. Markides ${ }^{\mathrm{a}}$

${ }^{a}$ Clean Energy Processes (CEP) Laboratory, Department of Chemical Engineering, Imperial College London, South Kensington Campus, London SW7 2AZ, UK

${ }^{\mathrm{b}}$ Department of Agro-environmental Sciences, University of Bari, Via Amendola 165/A, 70125 Bari, Italy

${ }^{c}$ Department of Mechanics, Mathematics and Management, Polytechnic of Bari, Via Re David 200, 70125 Bari, Italy

N.B. This is the accepted version of this article. The final, published version of the article can be found at https://doi.org/10.1016/j.enconman.2019.112053

\begin{abstract}
The high cost of organic Rankine cycle (ORC) systems is a key barrier to their implementation in waste heat recovery (WHR) applications. In particular, the choice of expansion device has a significant influence on this cost, strongly affecting the economic viability of an installation. In this work, numerical simulations and optimisation strategies are used to compare the performance and profitability of small-scale ORC systems using reciprocating-piston or single/two-stage screw expanders when recovering heat from the exhaust gases of a $185-\mathrm{kW}$ internal combustion engine operating in baseload mode. The study goes beyond previous work by directly comparing these smallscale expanders for a broad range of working fluids, and by exploring the sensitivity of project viability to key parameters such as electricity price and onsite heat demand. For the piston expander, a lumpedmass model and optimisation based on artificial neural networks are used to generate performance maps, while performance and cost correlations from the literature are used for the screw expanders. The thermodynamic analysis shows that two-stage screw expanders typically deliver more power than either single-stage screw or piston expanders due to their higher conversion efficiency at the required pressure ratios. The best fluids are acetone and ethanol, as these provide a compromise between the exergy losses in the condenser and in the evaporator in this application. The maximum net power output is found to be $17.7 \mathrm{~kW}$, from an ORC engine operating with acetone and a two-stage screw expander. On the other hand, the thermoeconomic optimisation shows that reciprocating-piston expanders show a potential for lower specific costs, and since such an expander technology is not mature, especially at these scales, this finding motivates further consideration of this component. A minimum specific investment cost of $1630 € / \mathrm{kW}$ is observed for an ORC engine with a piston expander, again with acetone as the working fluid. This system, optimised for minimum cost, also gives the shortest payback time of 4 years at an avoided electricity cost of $0.13 € / \mathrm{kWh}$. Finally, financial appraisals show a high sensitivity of the investment profitability to the value of produced electricity and to the heat-demand intensity. The comparison of these expansion devices, from both thermodynamic and economic perspectives, is of interest to the research community, developers and potential users of next-generation, small-scale ORC systems for WHR.
\end{abstract}

(C) 2019 The Authors. Published by Elsevier Ltd.

Keywords: combined heat and power, CHP, expanders, organic Rankine cycle, ORC, reciprocating-piston expander, screw expander, waste heat recovery, WHR

\footnotetext{
${ }^{*}$ Corresponding author. Tel.: +39 (0)80 5442869; Fax: +39 (0)80 5442830

E-mail: antonio.pantaleo@uniba.it; a.pantaleo@imperial.ac.uk
} 
Nomenclature

\section{Latin characters}

$60 \quad H$

$$
\text { area }\left[\mathrm{m}^{2}\right]
$$

$$
\text { cost }[€]
$$

specific heat capacity $\left[\mathrm{J} \cdot \mathrm{kg}^{-1} \cdot \mathrm{K}^{-1}\right]$

$\begin{array}{ll}c_{\mathrm{p}} & \text { specific heat } \\ D & \text { diameter }[\mathrm{m}]\end{array}$

$61 \quad h \quad$ heat transfer coefficient $\left[\mathrm{W} \cdot \mathrm{m}^{-2} \cdot \mathrm{K}^{-1}\right]$

$62 \quad \dot{I} \quad$ exergy destruction rate [W]

$63 \quad k \quad$ thermal conductivity $\left[\mathrm{W} \cdot \mathrm{m}^{-1} \cdot \mathrm{K}^{-1}\right]$

$64 \quad M \quad$ molar mass $[\mathrm{kg} / \mathrm{kmol}]$

$65 \quad m \quad$ mass $[\mathrm{kg}]$

$66 \quad \dot{m} \quad$ mass flow rate $\left[\mathrm{kg} . \mathrm{s}^{-1}\right]$

$67 \quad \mathrm{Nu} \quad$ Nusselt number [-]

$68 \quad p \quad$ pressure $[\mathrm{Pa}]$

$69 \quad \mathrm{Pr} \quad$ Prandtl number [-]

$70 \quad q \quad$ vapour quality [-]

$71 \quad \dot{Q} \quad$ heat flow rate $[\mathrm{W}]$

72 Re Reynolds number [-]

$73 \quad T \quad$ temperature [K]

$74 U \quad$ overall heat transfer coefficient $\left[\mathrm{W} \cdot \mathrm{m}^{-2} \cdot \mathrm{K}^{-1}\right]$

$75 \quad \dot{V} \quad$ volume flow rate $\left[\mathrm{m}^{3} \cdot \mathrm{s}^{-1}\right]$

$76 \quad V_{\mathrm{r}} \quad$ volume ratio [-]

$77 \dot{W} \quad$ power [W]

$78 \quad x \quad$ liquid-phase mass fraction [-]

$79 \quad \dot{X} \quad$ exergy flow rate [W]

$80 \quad X_{\mathrm{tt}} \quad$ Lockhart-Martinelli parameter [-]

$81 \quad y \quad$ vapour-phase mass fraction [-]

\section{Greek characters}

$86 \quad \eta \quad$ efficiency [-]

$87 \mu \quad$ dynamic viscosity [Pa.s]

$88 \quad$ density $\left[\mathrm{kg} \cdot \mathrm{m}^{-3}\right]$

89

90

91

$93 \quad 1,2,3,4$ working fluid states in the ORC

94 cond condenser

95 cs cooling stream

96 evap evaporator

97 ex exergy

98 exh exhaust gas

99 exp expander 


\begin{tabular}{|c|c|c|}
\hline 100 & fl & flux \\
\hline 101 & hs & heat source \\
\hline 102 & i & index \\
\hline 103 & in & inlet \\
\hline 104 & ip & inner pipe \\
\hline 105 & is & isentropic \\
\hline 106 & 1 & liquid \\
\hline 107 & $\operatorname{lm}$ & logarithmic mean \\
\hline 108 & $\max$ & maximum \\
\hline 109 & $\min$ & minimum \\
\hline 110 & op & outer pipe \\
\hline 111 & out & outlet \\
\hline 112 & pis & piston \\
\hline 113 & pump & pump \\
\hline 114 & $\mathrm{pp}$ & pinch point \\
\hline 115 & $\mathrm{r}$ & ratio \\
\hline 116 & $\mathrm{~s}$ & specific \\
\hline 117 & scr & screw \\
\hline 118 & sh & superheat \\
\hline 119 & $\mathrm{sp}$ & single phase \\
\hline 120 & tot & total \\
\hline 121 & tp & two phase \\
\hline 122 & $\mathrm{v}$ & vapour \\
\hline 123 & W & jacket water \\
\hline 124 & wf & working fluid \\
\hline 125 & & \\
\hline 126 & Abbrev & ations \\
\hline 127 & & \\
\hline 128 & CAMD & computer-aided molecular design \\
\hline 129 & CEPCI & chemical engineering plant cost index \\
\hline 130 & CHP & combined heat and power \\
\hline 131 & DPI & direct permanent investment \\
\hline 132 & GWP & global warming potential \\
\hline 133 & ICE & internal combustion engine \\
\hline 134 & IRR & internal rate of return \\
\hline 135 & LCOE & levelised cost of energy \\
\hline 136 & LHV & lower heating value \\
\hline 137 & MGT & micro gas-turbine \\
\hline 138 & NG & natural gas \\
\hline 139 & NPV & net present value \\
\hline 140 & ODP & ozone depletion potential \\
\hline 141 & ORC & organic Rankine cycle \\
\hline 142 & PBT & payback time \\
\hline 143 & PM & particulate matter \\
\hline 144 & SAFT & statistical associating fluid theory \\
\hline 145 & TES & thermal energy storage \\
\hline 146 & VOCs & volatile organic compounds \\
\hline 147 & WHR & waste-heat recovery \\
\hline
\end{tabular}




\section{Introduction}

Recent years have seen an increasing interest in the utilisation of renewable energy resources and in improving the energy efficiency of energy systems [1]. In this scenario, the use of the organic Rankine cycle (ORC) technology has attracted attention thanks to its suitability for converting lowtemperature heat to power [2]. After a couple of decades, starting from the 1980s, during which ORC systems were mainly employed in geothermal applications, this technology has experienced significant growth, with an average annual installed capacity between $75 \mathrm{MW}$ and $200 \mathrm{MW}$, reaching an installed capacity of $\sim 350 \mathrm{MW}$ in 2015 . By the beginning of 2017 , ORC technology had a total installed capacity close to $3 \mathrm{GW}$, distributed over 1750 systems [3].

Geothermal power is an important sector for ORC technology, in particular in relation to large scale plants, reaching a share of almost $75 \%$ of all installed ORC system capacity in 2009 , concentrated in a relatively small number of systems (less than 350). Biomass ORC applications represented $12 \%$ of all installed capacity at the start of 2017 [3], with many of these being medium- to small-scale systems. Some solutions include the hybridisation of biomass cycles with the combined use of natural gas, in order to achieve higher conversion efficiencies and overcome issues of seasonality and logistics of biomass supply [4-8]. Solar applications are not competitive so far, due to the high investment cost of the solar collectors, which make the whole ORC systems more expensive than photovoltaic panels with electricity storage. However, hybrid solutions such as concentrating solar/biomass systems with ORC combined cycles have been proposed recently at research and pre-commercial scales $[9,10]$.

Waste heat recovery (WHR) via ORC systems is a more recent market, which is particularly promising to increase the efficiency of energy conversion systems and reduce pollution emissions at large scale [11-13]. Several major companies are active in this market, with large- and mediumscale systems recovering heat mainly from gas turbines, internal combustion engines (ICEs) or industrial processes. WHR applications accounted for almost 15\% of the total ORC market in 2017, with a relevant number of small-size $(<4 \mathrm{~kW})$ systems in operation [3], representing a secondary market for ORC systems and experiencing a fast growth over the last years. Multiple industrial processes may benefit from such WHR technologies. Despite their apparently large heat recovery potential, cement and lime or glass industries account for only a small share of the heat recovery market. Landfill and biogas engines are the focus of many ORC manufacturers that offer small units (up to $200 \mathrm{~kW}$ ), thanks to incentives in different countries [14]. A number of recent studies have focused on the optimisation of ORC systems for small-scale WHR technologies. In particular, an optimisation framework to maximise power and minimise fuel consumption of an integrated ICE with bottoming ORC engine was proposed by Chatzopoulou and Markides [15], reporting a total power output increase of $30 \%$ in comparison to nominal system design, due to the modulation of exhaust gas temperature to increase the ORC system performance.

The capital cost of an ORC system is a crucial deciding factor in the implementation of this WHR technology. Manufacturers offer ORC solutions in a broad range of power outputs and temperature levels for different applications. In this work, cost data is presented from a number of companies and summarised in Figure 1 as a function of the power output. The scatter of the data is due to different integration costs and pricing strategies for each manufacturer. Thus, while specific costs should not be generalised, the results serve to illustrate the general trend. 


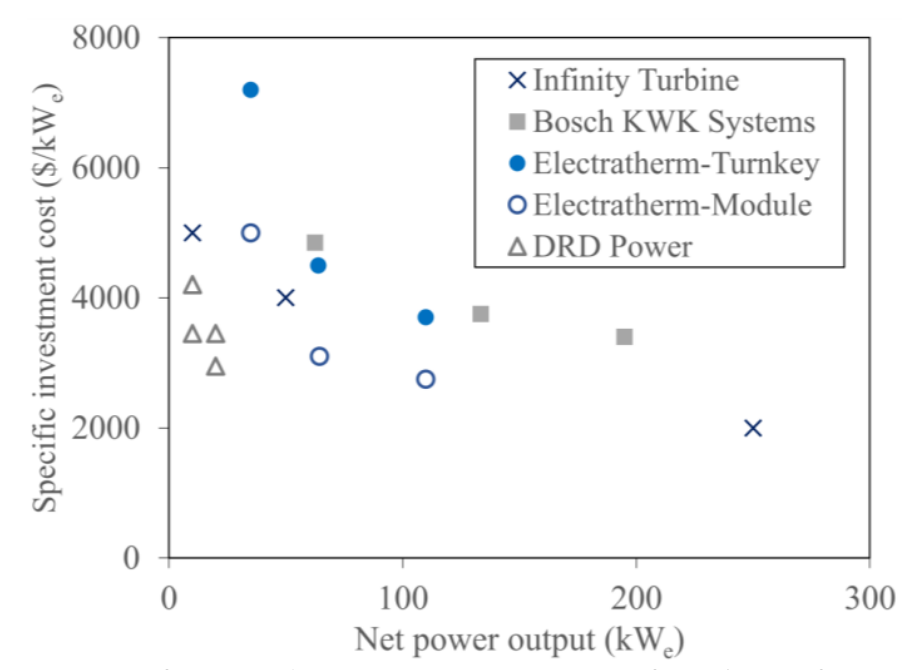

Figure 1: Specific costs of several ORC systems as a function of power output (authors' interpretation of manufacturer data).

As expected, the specific cost decreases when the power output increases. However, Figure 1 reports the "turnkey costs" (except for Electratherm), that are hence not limited to the module costs (sum of the unitary component costs) but include engineering, procurement, installation and insurance. The costs are aligned to those obtained from the proposed cost assessment methodology.

One of the most critical components of a cost-effective ORC system for WHR is the expansion device. In general, since the typical power output is in the small-medium range $\left(5-300 \mathrm{~kW}_{\mathrm{e}}\right)$, volumetric expanders are preferred to turbines [16]. Their isentropic efficiency mainly depends on valve pressure losses, friction, mass-leakage, and thermal losses, which are themselves influenced by the expander operating conditions. In particular, the pressure ratio imposed on the expander is the main parameter influencing its performance. Positive-displacement expanders have a built-in volume ratio (usually in the range $2-7$ ), which is linked to the design pressure ratio by the fluid thermodynamic properties. In theory, the optimal design pressure ratio should match the system pressure ratio - defined as the ratio between the ORC evaporating and condensing pressures. However, for a given volumetric expansion machine, the maximum power output can be achieved in under-expansion or over-expansion working conditions due to the influence of the other loss mechanisms $[17,18]$. The selection criteria for the expanders for ORC-based micro-CHP systems are discussed by Qiu et al. [19], proposing an assessment of the market trends of turbine, screw, scroll and vane expanders, and concluding that scroll and vane expanders are likely to be the best candidates for ORC-based micro-CHP systems within the capacity range of $1-10 \mathrm{~kW}_{\mathrm{e}}$. A review of working fluids and expanders for ORC systems is also available from Bao and Zhao [20], together with the assessment of key parameters for expander selection, such as the isentropic efficiency, pressure ratio, power output, lubrication, rotational speed, dynamic balance, reliability, cost, working temperatures and pressures, leakage flows, noise and safety. The paper provides an up-to-date assessment of prototypes of various types of expansion machines. Other researchers [21,22] review similar expander technologies for small-scale applications, recognising that there are several gaps in the optimisation of expansion machines, and that micro-scale expanders suitable for ORC systems are not yet commercially available. Song et al. [23] discuss the performance of scroll expanders and the main technical limitations for ORC applications, assessing the related simulation and optimisation methods.

Scroll and rotary expanders have been shown to be suitable for small sizes, i.e., below $10 \mathrm{~kW}$, with typical built-in volume ratios below 5 . In the medium power output range, i.e., $10-300 \mathrm{~kW}$, screw- 
type expanders are considered the most suitable positive-displacement devices. Two types of screw expanders are usually employed: single-screw expanders and twin-screw expanders. The latter are found to be more cost-effective for power production [24], while recent studies that focused on singlescrew expanders for WHR applications demonstrated that they can achieve isentropic efficiency above $70 \%$ [24]. At intermediate power output scales $(\sim 10-100 \mathrm{~kW})$, reciprocating-piston machines can be cost-competitive with respect to other positive-displacement machines. In particular, there is a renewed interest in their use in small-scale steam and ORC systems [25].

The inherent advantages of reciprocating-piston expanders over other positive-displacement machines are their ability to provide higher built-in volume ratios, and robust part-load performance. Moreover, they can withstand high operating pressures and temperatures, and work at low rotational speeds. However, pressure losses through the valves, gas-to-wall heat transfer, mass leakage and friction may limit their efficiency. Therefore, pressure losses must be minimised with a careful valve design and timing strategies, while effective lubrication is needed to limit friction losses. The unsteady heat transfer between the gas and the cylinder walls, and the mass leakage of gas between the piston and the cylinder, remain relatively challenging to predict and address. These issues are currently a matter of investigation to enable the design of high-efficiency machines [26].

Another important area of research in ORC optimisation is the selection of the working fluid. Bao and Zhao [20] provided an extensive review of fluids and their selection for ORC applications based to thermodynamic performance indicators and environmental or safety aspects. Oyewunmi et al. [27] proposed a specific optimisation of pure working fluids and mixtures of fluids for ORC systems, demonstrating that: (i) the temperature glide during isobaric evaporation/condensation of working fluid mixtures provides a better thermal match to the heat-source/sink streams, thus improving overall performance; (ii) a whole system energy optimisation should include the possibility to use the cogenerated heat from the ORC system condenser, optimising the condensing temperature. White et al. $[28,29]$ described the use of computer-aided molecular design (CAMD) tools, based on statistical associating fluid theory (SAFT), for the thermodynamic modelling and optimisation of ORC systems, together with heat-exchanger sizing models, component cost correlations and thermoeconomic assessments. Both the ORC engine components and working fluid are therefore optimised in a single step and over a wide range of heat-source conditions.

Despite the wide literature on working-fluid selection for ORC systems in different applications, little attention has been paid so far to the combined selection and optimisation of the expansion machine and the working fluid, which is a specific focus of this paper. In particular, this work aims at investigating the performance and profitability of ORC systems for heat recovery from ICEs, which presents a global installed capacity of about $400 \mathrm{MW}$ and $65 \%$ of the total installed ORC capacity [3]. In such applications, the power generated by the ORC system lies in the range of 10 to $20 \mathrm{~kW}_{\mathrm{e}}$, where screw and piston expanders are promising candidates in terms of energy performance and investment profitability. In particular, a single-stage screw expander, a two-stage screw expander and a single-stage piston expander are compared. Simulations are performed for 18 suitable fluids, chosen on the basis of their low global warming potential, ozone depletion potential, health hazard and instability hazard. Thermodynamic and thermoeconomic optimisations of the ORC system are performed in order to find the optimal configurations for each fluid and expander, comparing the performance of different technical solutions.

Finally, an economic feasibility study of the optimal ORC unit is proposed, using: (i) an analysis of component costs; and (ii) cost data from manufacturers relating to installation, operation and maintenance. The profitability of the investment is analysed through the metrics of net present 
value and internal rate of return, exploring the sensitivity of the economic viability to key factors

The proposed comparison of expanders and working fluids illustrates the key technoeconomic factors needed to facilitate the implementation of such technologies, assisting policymakers to set up support measures and investors to select promising market segments. The results also provide useful insights for manufacturers about the best working fluids, opportunities for improved efficiency, and promising expansion devices.

The paper is organised as follows: Sections 2 and 3 provide details of the thermodynamic and cost models used in this work, with working fluid selection discussed in Section 4. Section 5 describes the thermodynamic and thermoeconomic optimisation and provides a discussion of related results. The economic analysis is presented in Section 6. Finally, conclusions are drawn in Section 7.

\section{Thermodynamic model}

This section provides the characteristics of the ICE considered in the present work, and the details of the thermodynamic model developed and employed to simulate the performance of the ORC systems recovering heat from the ICE. In particular, the models employed for the screw and piston expanders are discussed. The performance map proposed by Astolfi [30], who correlated the optimal efficiency of a number of different screw expander designs against volume ratio and volumetric flow rate, has been used to model the screw expanders. This map provides an estimate of full-load performance at different operating points. For the piston expanders, a lumped-mass model of the expander [31] and an optimisation algorithm based on artificial neural networks are used to generate performance maps over a wide range of mass flow rates and pressure ratios. The performance data for the expanders are then combined with models of the heat exchangers and the pump to develop a thermodynamic model of the overall ORC system.

\subsection{ICE model}

The application considered in this work concerns the recovery of heat from the exhaust gases of a $185-\mathrm{kW}_{\mathrm{e}}$ natural-gas reciprocating ICE for stationary energy cogeneration. In particular, this work is based on an ICE, which is a combined heat and power (CHP) unit supplied by company ENER-G (now Centrica). The engine drives an alternator to produce electricity, while heat is recovered from the exhaust, jacket water and oil cooling circuits. The technical data of the ICE considered in this work are reported in Tables 2 and 3.

Table 2: Technical data of the ENER-G/Centrica E185 (low NO ${ }_{\mathrm{x}}$ ) natural gas ICE.

\begin{tabular}{lrlr}
\hline Number of cylinders & 12 & Compression ratio & 12 \\
Configuration & $90^{\circ} \mathrm{V}$ & Working procedure & 4-stroke \\
Displacement (L) & 22 & Engine rated speed (rpm) & 1500 \\
\hline
\end{tabular}

According to the manufacturer's data, the molar composition of the exhaust gases is: $\mathrm{N}_{2}=73.7 \%$, $\mathrm{O}_{2}=12.9 \%, \mathrm{CO}_{2}=8.9 \%, \mathrm{H}_{2} \mathrm{O}=3 \%, \mathrm{Ar}=1.5 \%$. The assumed backpressure is 1.1 bar. The exhaust temperature of the engine is estimated by REFPROP 9.1 [32] and the calculated temperature showed a difference of only $0.35 \%$ with respect to the nominal value. 
Table 3: Performance of the selected ICE-based CHP unit. The available thermal power is calculated assuming that the exhaust gases and jacket water are cooled down to $120^{\circ} \mathrm{C}$ and $80^{\circ} \mathrm{C}$, respectively.

\begin{tabular}{lrlr}
\hline Electrical output $(\mathrm{kW})$ & 185 & Thermal power from exhaust gas $(\mathrm{kW})$ & 98 \\
Electrical efficiency $(\%)$ & 33.6 & Thermal power from jacket water $(\mathrm{kW})$ & 210 \\
Thermal power output $(\mathrm{kW})$ & 308 & Exhaust mass flow rate $(\mathrm{kg} / \mathrm{h})$ & 721 \\
Thermal efficiency $(\%)$ & 56.1 & Water inlet temperature $\left({ }^{\circ} \mathrm{C}\right)$ & 90 \\
Total efficiency $(\%)$ & 89.7 & Water mass flow rate $(\mathrm{kg} / \mathrm{s})$ & 5.0 \\
Exhaust gas temperature $\left({ }^{\circ} \mathrm{C}\right)$ & 570 & & \\
\hline
\end{tabular}

327

328

329

330

331

332

333

334

335

336

337

338

339

340

341

342

343

344

345

346

While $68 \%$ of the total heat is rejected in the jacket cooling water system (against $32 \%$ in the exhaustgas stream), as shown in Table 3, this work is focused on the recovery of the waste heat from the exhaust gases, as the thermal energy in this stream is available at significantly higher temperatures. An exergy analysis supports this choice, by determining the maximum useful power that can be produced with a reversible heat engine recovering heat from the exhaust-gas, $\dot{X}_{\mathrm{exh}}$, and jacket-water streams, $\dot{X}_{\mathrm{w}}$ :

$$
\begin{aligned}
& \dot{X}_{\text {exh }}=\dot{m}_{\text {exh }}\left[h_{\text {exh,in }}-h_{\text {exh,out }}-T_{0}\left(s_{\text {exh,in }}-s_{\text {exh,out }}\right)\right], \\
& \dot{X}_{\mathrm{w}}=\dot{m}_{\mathrm{w}}\left[h_{\mathrm{w}, \text { in }}-h_{\mathrm{w}, \text { out }}-T_{0}\left(s_{\mathrm{w}, \text { in }}-s_{\mathrm{w}, \text { out }}\right)\right] .
\end{aligned}
$$

In the analysis, the exhaust gases are cooled down to $T_{\text {exh,out }}=120{ }^{\circ} \mathrm{C}$ and the jacket water down to $T_{\mathrm{w}, \text { out }}=80^{\circ} \mathrm{C}$, according to the limits specified by the manufacturer.

Figure 2 shows that, although twice as much thermal power is released in the jacket water as in the exhaust gases, the reversible power output is higher for the exhaust gases as their temperature is much higher. More than half of the thermal power available in the exhaust gas flow $(50.5 \%$, i.e., $49.5 \mathrm{~kW}$ ) has the potential to be converted into useful work, compared to only $18.1 \%$ (i.e., $38 \mathrm{~kW}$ ) for the jacket water. This analysis justifies the choice to recover heat from the exhaust gases rather than from the jacket water. In addition, hot water from the jacket could be easily used for space heating at medium-low temperature, while exhaust gases at higher temperature can be used for electricity generation using ORC systems.

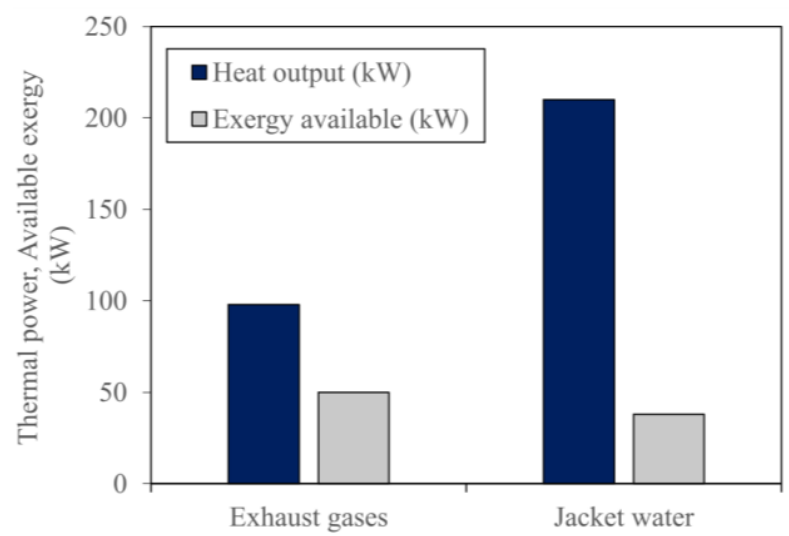

Figure 2: Thermal power and reversible power output available for the E185 ICE.

\subsection{ORC system model}

A sub-critical and non-regenerative cycle configuration is considered in this work (see Figure 3 ). Although a regenerator can improve ORC engine performance, it is not included in the present work as it would lead to increased heat exchanger costs and system complexity with only minor 
performance improvements [33]. Since the power generated by the ORC system is in the range of 10 to $20 \mathrm{~kW}_{\mathrm{e}}$, a screw expander and a reciprocating-piston expander are selected for the energy conversion process. Turbines can be challenging to design for this power range because of their need to operate at very high rotational speeds.

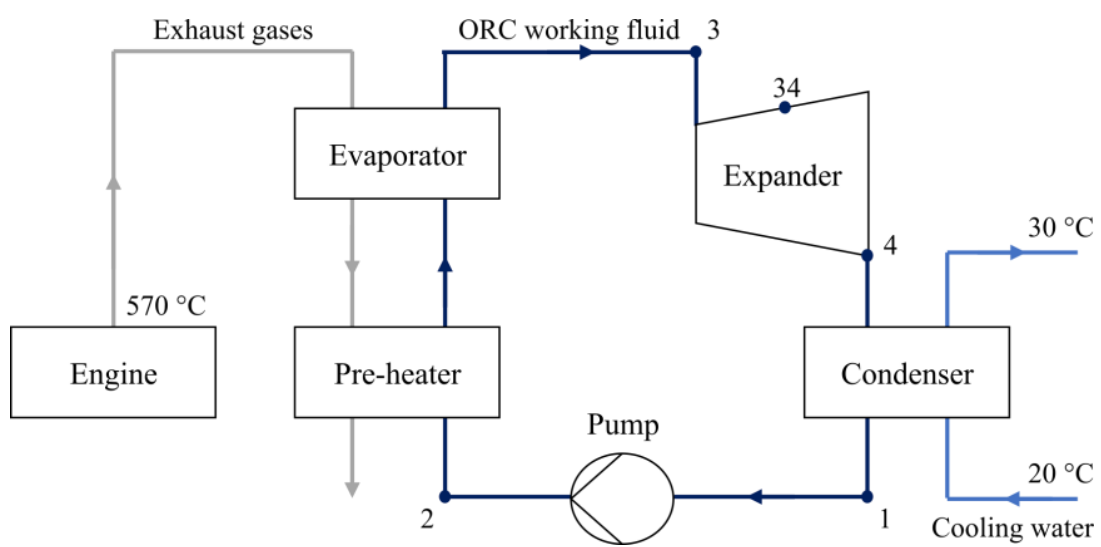

Figure 3: Schematic of the ORC system recovering heat from the internal combustion engine exhaust gases and rejecting heat to cooling water.

Of the selected expander types, screw expanders are the more mature technology, with the following advantages: (i) compact design [18]; (ii) capability to adjust the volume ratio with the use of a slide valve in order to maximise the device efficiency at off-design conditions [30]; and (iii) capability to handle expansion in the presence of liquid droplets in two-phase flow. On the other hand, reciprocating-piston expanders show high isentropic efficiencies at high pressure ratios and good part-load performance. Relative to screw machines, their use for two-phase expansion needs to be approached with care, and although losses arise due to valve flows and the clearance volume, they can typically achieve lower leakage rates.

Many ORC engine studies assume a constant isentropic efficiency for the expander, which can lead to operating points that are challenging to achieve in practice. An alternative approach is to incorporate expander performance maps within the cycle optimisation, helping to ensure optimal matching of the cycle and expander. Astolfi [30] collated data on a set of Bitzer open-screw compressors and mapped their efficiency against volume ratio and volumetric flow rate. As the compressors can be converted into expanders with relatively minor modifications, this dataset can be used as a surrogate for screw expander performance. As a range of machines were considered, the resulting surface fit gives an estimate for possible full-load performance available at different operating points.

Performance maps for reciprocating-piston expanders cannot be generated in the same way. This is due to the fact that piston expanders require active valve control, unlike piston compressors, which operate with passively-actuated valves. The performance maps are therefore obtained via a dynamic lumped-mass model [31], developed in MATLAB. The model incorporates valve losses, heat transfer and leakage flows, and both the model formulation and validation are described in greater detail by Chatzopoulou [34]. A set of decision variables is used to parameterise a generic expander design, including the bore, stroke, clearance height, and valve opening and closing times. An optimisation routine has been developed to identify high-performing designs over a range of operating conditions, according to the methodology outlined in Simpson et al. [35]. For each operating condition, the objective function is to maximise power output per unit mass flow rate of working fluid. An artificialneural-network surrogate model is used to fit a surface to the outputs of the lumped-mass model 
(mass flow rate and isentropic efficiency) for different designs and operating conditions, which can then be evaluated rapidly during an optimisation using a genetic algorithm approach. An iterative approach is followed, with further lumped-mass model evaluations used to refine the neural-network surrogate with each iteration. The resulting designs are combined into performance maps across a range of mass flow rates, pressure ratios and expander inlet temperatures. The properties of the organic working fluid (wf) are calculated using REFPROP 9.1 [32].

In this work, three configurations are analysed for the expansion process: a single-stage screw expander, a single-stage piston expander and a two-stage screw expander, in a series configuration. A two-stage piston expander is not considered because of the higher pressure-ratio capability of the piston expander within a single stage.

The following assumptions are considered for the ORC system model:

- Each component of the cycle operates under steady-state conditions.

- Heat losses to or from the surroundings are neglected.

- Friction losses in the connecting pipes are neglected.

- Kinetic and potential energy of the flowing fluid are neglected.

- Heat transfer in the heat exchangers is calculated for fully-developed flow.

The basic equations for the energy analysis are given below.

The power required to pump the working fluid from State 1 (saturated liquid) to State 2 in Figure 4 is:

$$
\dot{W}_{\text {pump }}=\dot{m}_{\mathrm{wf}}\left(h_{2}-h_{1}\right)=\frac{\dot{m}_{\mathrm{wf}}\left(h_{2, \text { is }}-h_{1}\right)}{\eta_{\text {is,pump }}},
$$

where $\eta_{\text {is,pump }}$ is the pump isentropic efficiency, defined as:

$$
\eta_{\text {is,pump }}=\frac{h_{2, \text { is }}-h_{1}}{h_{2}-h_{1}} .
$$

To study the influence of the superheating on the performance of the system, a non-dimensional parameter, $d_{\mathrm{SH}}$, (which can vary between 0 and 1 ) is employed. It is known that in some case the superheating is detrimental for the performance of the cycle and this parameter allows the working fluid to exit the heating process either as saturated vapour or as superheated vapour:

$$
d_{\mathrm{SH}}=\frac{T_{3}-T_{3 \mathrm{v}}\left(p_{\text {evap }}\right)}{T_{\max }-T_{3 \mathrm{v}}\left(p_{\text {evap }}\right)} .
$$

Here, $T_{\max }$ is the maximum temperature of the working fluid, defined as follows:

$$
T_{\mathrm{max}}=\left\{\begin{array}{ll}
T_{\mathrm{hs}, \mathrm{in}}-\Delta T_{\mathrm{pp}} & \text { if } T_{\mathrm{max}, \mathrm{wf}}>T_{\mathrm{hs}, \mathrm{in}}-\Delta T_{\mathrm{pp}} \\
T_{\mathrm{max}, \mathrm{wf}} & \text { if } T_{\mathrm{max}, \mathrm{wf}}<T_{\mathrm{hs}, \mathrm{in}}-\Delta T_{\mathrm{pp}}
\end{array},\right.
$$

where $\Delta T_{\mathrm{pp}}$ is the minimum allowed temperature difference at the pinch point; $T_{\max , \mathrm{wf}}$ is the by REFPROP 9.1. Thus, the heat extracted from the heat source (hs) is given by: 


$$
\dot{Q}_{\text {in }}=\dot{m}_{\mathrm{hs}}\left(h_{\mathrm{hs}, \text { in }}-h_{\mathrm{hs}, \text { out }}\right) \text {, }
$$

which is equal to the heat transferred to the working fluid:

$$
\dot{Q}_{\mathrm{in}}=\dot{m}_{\mathrm{wf}}\left(h_{3}-h_{2}\right) \text {. }
$$

If a single-stage expansion is considered, the power generated by the expander is:

$$
\dot{W}_{\text {exp }}=\dot{m}_{\mathrm{wf}}\left(h_{3}-h_{4}\right)=\eta_{\mathrm{is}, \exp } \dot{m}_{\mathrm{wf}}\left(h_{3}-h_{4, \mathrm{is}}\right) \text {. }
$$

In the case of two-stage expansion, defining the outlet of the first expander as ' 34 ', and the isentropic exit state as ' 34 ,is', the generated power is the sum of the following two contributions:

$$
\begin{aligned}
& \dot{W}_{\text {exp }, 1}=\dot{m}_{\mathrm{wf}}\left(h_{3}-h_{34}\right)=\eta_{\mathrm{is}, \exp 1} \dot{m}_{\mathrm{wf}}\left(h_{3}-h_{34, \mathrm{is}}\right), \text { and } \\
& \dot{W}_{\mathrm{exp}, 2}=\dot{m}_{\mathrm{wf}}\left(h_{34}-h_{4}\right)=\eta_{\mathrm{is}, \exp 2} \dot{m}_{\mathrm{wf}}\left(h_{34}-h_{4, \mathrm{is}}\right) .
\end{aligned}
$$

where the isentropic efficiency of the screw expander is provided by Astolfi [30] as:

$$
\begin{aligned}
& \eta_{\mathrm{is}, \mathrm{scr}}=c\left[0.940+0.0293 \ln \left(\dot{V}_{\text {out }}\right)-0.0266 V_{\mathrm{r}}\right], \text { with } \\
& c=1-0.264 \ln \left(\frac{V_{\mathrm{r}}}{7}\right) \quad \text { for } V_{\mathrm{r}}>7,
\end{aligned}
$$

with $\dot{V}_{\text {out }}$ being the isentropic volumetric flow rate at the outlet of the expander and $V_{\mathrm{r}}$ the volume ratio across the stage.

For the piston expander, a 3-D lookup table of isentropic efficiency as a function of mass flow rate, pressure ratio and superheat temperature, $T_{\mathrm{sh}}$, is used for each fluid:

$$
\eta_{\mathrm{is}, \mathrm{pis}}=f\left(\dot{m}_{\mathrm{wf}}, \frac{p_{\text {evap }}}{p_{\text {cond }}}, T_{\mathrm{sh}}\right) .
$$

After the expander, the working fluid rejects heat to the cooling stream (cs). The thermal power output from the working fluid is given by:

$$
\dot{Q}_{\text {out }}=\dot{m}_{\mathrm{wf}}\left(h_{4}-h_{1}\right) \text {, }
$$

which is equal to the heat received by the cooling stream:

$$
\dot{Q}_{\text {out }}=\dot{m}_{\mathrm{cs}}\left(h_{\mathrm{cs}, \text { out }}-h_{\mathrm{cs}, \mathrm{in}}\right) \text {. }
$$

464 and the first-law efficiency (also referred to as thermal efficiency) is defined as: 


$$
\eta_{\mathrm{th}}=\frac{\dot{W}_{\text {net }}}{\dot{Q}_{\text {in }}}
$$

The loss of useful energy of the system or device is not quantified by the first law of thermodynamics since it does not make a distinction between quality and quantity of energy [36]. The exergy analysis, based on the second law of thermodynamics, is a useful method in the design, evaluation, optimisation and improvement of energy systems. From this analysis, it is possible to understand the location, cause and magnitude of the lost potential to do work in an energy conversion system.

In the current work, the heat sink inlet temperature $\left(20^{\circ} \mathrm{C}\right)$ and atmospheric pressure $(1 \mathrm{~atm})$ are taken as the reference state. The equations for the ORC system exergy analysis are given below.

The exergy received by the fluid in the pump is:

$$
\dot{X}_{\text {pump }}=\dot{m}_{\mathrm{wf}}\left[h_{2}-h_{1}-T_{0}\left(s_{2}-s_{1}\right)\right],
$$

while the destroyed exergy in the pump is:

$$
\dot{I}_{\text {pump }}=T_{0} \dot{m}_{\mathrm{wf}}\left(s_{2}-s_{1}\right) \text {. }
$$

The exergy supplied by the heat source is computed as:

$$
\dot{X}_{\mathrm{hs}}=\dot{m}_{\mathrm{hs}}\left[h_{\mathrm{hs}, \text { in }}-h_{\mathrm{hs}, \text { out }}-T_{0}\left(s_{\mathrm{hs}, \text { in }}-s_{\mathrm{hs}, \text { out }}\right)\right] .
$$

The exergy received by the working fluid is:

$$
\dot{X}_{\mathrm{wf}, \mathrm{in}}=\dot{m}_{\mathrm{wf}}\left[h_{3}-h_{2}-T_{0}\left(s_{3}-s_{2}\right)\right] .
$$

Therefore, the destroyed exergy in the evaporator is:

$$
\dot{I}_{\text {evap }}=\dot{X}_{\mathrm{hs}}-\dot{X}_{\mathrm{wf}, \text { in }}=T_{0}\left[\dot{m}_{\mathrm{hs}}\left(s_{\mathrm{hs}, \text { out }}-s_{\mathrm{hs}, \text { in }}\right)+\dot{m}_{\mathrm{wf}}\left(s_{3}-s_{2}\right)\right] .
$$

The available exergy for a single stage expansion is:

$$
\dot{X}_{\text {exp }}=\dot{m}_{\mathrm{wf}}\left[h_{3}-h_{4}-T_{0}\left(s_{3}-s_{4}\right)\right] \text {, }
$$

and the destroyed exergy in the expander is given by:

$$
\dot{I}_{\text {exp }}=T_{0} \dot{m}_{\mathrm{wf}}\left(s_{4}-s_{3}\right) \text {. }
$$

Exergy supplied to the cooling water during the condensation process is:

$$
\dot{X}_{\text {cond }}=\dot{m}_{\mathrm{wf}}\left[h_{4}-h_{1}-T_{0}\left(s_{4}-s_{1}\right)\right] \text {. }
$$

The exergy received by the cooling water is computed as:

$$
\dot{X}_{\mathrm{cs}}=\dot{m}_{\mathrm{cs}}\left[h_{\mathrm{cs}, \mathrm{out}}-h_{\mathrm{cs}, \text { in }}-T_{0}\left(s_{\mathrm{cs}, \mathrm{out}}-s_{\mathrm{cs}, \text { in }}\right)\right] .
$$


and the destroyed exergy in the condenser is:

$$
\dot{I}_{\text {cond }}=\dot{X}_{\text {cond }}-\dot{X}_{\mathrm{cs}}=T_{0}\left[\dot{m}_{\mathrm{wf}}\left(s_{1}-s_{4}\right)+\dot{m}_{\mathrm{cs}}\left(s_{\mathrm{cs}, \text { out }}-s_{\mathrm{cs}, \text { in }}\right)\right] .
$$

Finally, the total flow rate of the irreversibility in the ORC system is the sum of destroyed exergy in each component:

$$
\dot{I}_{\text {tot }}=\sum_{i \in \text { Components }} \dot{I}_{i}
$$

and the final exergy balance of ORC system is written as:

$$
\dot{X}_{\mathrm{hs}}+\dot{W}_{\text {pump }}=\dot{W}_{\text {exp }}+\dot{X}_{\text {cs }}+\dot{I}_{\text {tot }} .
$$

The exergy (second-law) efficiency is computed by the following equation:

$$
\eta_{\mathrm{ex}}=\frac{\dot{W}_{\mathrm{exp}}-\dot{W}_{\mathrm{pump}}}{\dot{X}_{\mathrm{hs}}},
$$

where the available input exergy is the exergy change in the heat source calculated by Eq. (21).

In order to obtain a low-cost configuration, counter-current double-pipe heat exchangers are chosen. The heat addition process takes place in two heat exchangers: a pre-heater $(\mathrm{PH})$ used to heat the working fluid to saturated liquid and an evaporator (Ev) in which the working fluid is vaporised and superheated if necessary. Likewise, the heat rejection process is carried out in a desuperheater (DSh) and a condenser $(\mathrm{Cn})$. The former brings the working fluid to saturated vapour from the expander outlet whereas the latter condenses it to saturated liquid.

The heat exchanger designs are carried out considering standard/nominal pipe diameters. The sizes are selected to provide turbulent flow regimes for each fluid, while maintaining reasonably low velocities in both pipes. In particular, velocities of $1.5 \mathrm{~m} / \mathrm{s}$ for liquids and $30 \mathrm{~m} / \mathrm{s}$ for vapour are considered as upper limits [37]. The heat exchangers are assumed to be constructed in stainless steel (thermal conductivity $k=24 \mathrm{~W} \cdot \mathrm{m}^{-1} \cdot \mathrm{K}^{-1}$ since they must withstand hot organic fluids and/or exhaust gases).

For modelling purposes, each heat exchanger is discretised into 100 segments of varying size (along their length), with an equal quantity of heat transferred in each. In all heat exchangers, the working fluid flows through the inner pipe (ip) whereas the heat source and sink stream through the outer pipe (op). A segment is depicted in Figure 4.

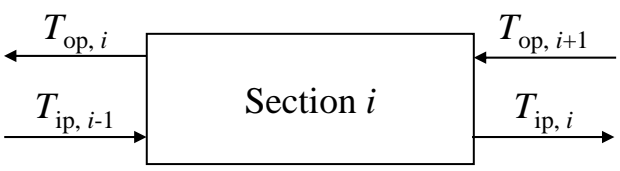

Figure 4: Heat exchanger segment (op: outer pipe; ip: inner pipe).

Thus, the total heat fluxes transferred to/from the working fluid (referring to Eqs. (8) and (15), respectively) are given by: 


$$
\begin{aligned}
& \dot{Q}_{\mathrm{in}}=\dot{Q}_{\mathrm{PH}}+\dot{Q}_{\mathrm{Ev}}=\sum_{i=1}^{100} \dot{Q}_{\mathrm{PH}, i}+\sum_{i=1}^{100} \dot{Q}_{\mathrm{Ev}, i} \\
& \dot{Q}_{\mathrm{out}}=\dot{Q}_{\mathrm{DSh}}+\dot{Q}_{\mathrm{Cn}}=\sum_{i=1}^{100} \dot{Q}_{\mathrm{DSh}, i}+\sum_{i=1}^{100} \dot{Q}_{\mathrm{Cn}, i}
\end{aligned}
$$

542 For each segment $i$, an overall heat transfer coefficient $U_{i}$, is calculated as follows:

544

545

546

547

548

549

550

$$
\frac{1}{U_{i}}=\frac{1}{h_{\mathrm{op}, i}}+\frac{\Delta x}{k}+\frac{1}{h_{\mathrm{ip}, i}}
$$

Once the overall heat-transfer coefficient for each segment is known, the heat transfer area can be calculated from the following equation for counter-current flows:

$$
\dot{Q}_{i}=U_{i} A_{i} \Delta T_{\mathrm{lm}, i},
$$

where $\Delta T_{\mathrm{lm}, i}$ is the logarithmic average temperature difference for the segment $i$ :

$$
\Delta T_{\mathrm{lm}, i}=\frac{\left(T_{\mathrm{op}, i+1}-T_{\mathrm{ip}, i}\right)-\left(T_{\mathrm{op}, i}-T_{\mathrm{ip}, i-1}\right)}{\ln \left(\frac{T_{\mathrm{op}, i+1}-T_{\mathrm{ip}, i}}{T_{\mathrm{op}, i}-T_{\mathrm{ip}, i-1}}\right)} .
$$

Single-phase (sp) and two-phase (tp) local heat transfer coefficients (HTCs) are calculated as follows. For single-phase flow, the local HTCs $\left(h_{\mathrm{op}, \mathrm{i}}, h_{\mathrm{p}, \mathrm{i}}\right)$ are computed using the well-known Dittus-Boelter Nusselt $\left(N u_{\mathrm{sp}, i}\right)$ number correlation.

$$
N u_{\mathrm{sp}, i}=0.023 \cdot R e_{i}^{0.8} \cdot \operatorname{Pr}_{i}^{n}
$$

where the exponent $n$ is 0.3 for cooling and 0.4 for the heating.

Defining $\dot{m}_{\mathrm{fl}}$ as the mass flux, $D_{\mathrm{ip}}$ as the inner pipe diameter, $\mu$ as the dynamic viscosity, $k$ as the thermal conductivity and $c_{\mathrm{p}}$ as the isobaric specific heat capacity, the Reynolds and Prandtl numbers are computed as follows:

$$
\dot{m}_{\mathrm{fl}}=\frac{4 \cdot \dot{m}_{\mathrm{wf}}}{\pi D_{\mathrm{ip}}^{2}} ; R e_{i}=\frac{\dot{m}_{\mathrm{fl}} D_{\mathrm{ip}}}{\mu_{i}} ; \operatorname{Pr}_{i}=\frac{c_{p_{i}} \mu_{i}}{k_{i}}
$$

Thus, the local HTC for the working fluid side is given as:

$$
h_{\mathrm{ip}, i}=\frac{N u_{\mathrm{sp}, i} \cdot k_{i}}{D_{\mathrm{ip}}}
$$

The local HTCs in the two-phase regions of the heat exchangers is calculated from the two-phase Nusselt number, $N u_{\mathrm{tp}, i}$, obtained by modifying the single-phase Nusselt number, $N u_{\mathrm{sp}, i}$, with empirical correlations of the Lockhart-Martinelli parameter, $X_{\mathrm{tt}}[38,39]$ : 


$$
\begin{aligned}
& N u_{\mathrm{tp}, i}=F\left(X_{\mathrm{tt}}\right) N u_{\mathrm{sp}, i} ; F\left(X_{\mathrm{tt}}\right)=1+1.8\left(\frac{1}{X_{\mathrm{tt}}}\right)^{0.82}, \\
& X_{\mathrm{tt}}=\left(\frac{1-q}{q}\right)^{0.9}\left(\frac{\rho_{\mathrm{v}}}{\rho_{\mathrm{l}}}\right)^{0.5}\left(\frac{\mu_{\mathrm{l}}}{\mu_{\mathrm{v}}}\right)^{0.1}, \\
& h_{\mathrm{ip}}=\frac{N u_{\mathrm{tp}, i} \cdot k_{i}}{D_{\mathrm{ip}}}\left[1-0.533(|y-x|)^{0.828}\right],
\end{aligned}
$$

571

572

573

574

575

576

577

578

579

580

581

582

583

584

where $q$ is the vapour quality (on a mass basis) and $x$ and $y$ are the liquid- and vapour-phase composition (mass fractions). Equations (40) and (41) can be directly applied for pure fluids using the overall composition for the liquid and vapour-phase properties [40]. The total heat transfer area is given by the sum of the areas for all segments is calculated from Eq. (35).

\section{Cost estimation}

To obtain reliable results from the thermoeconomic analysis, accurate information about the equipment costs are needed. Engineering companies and component manufacturers hold this data but treat it as confidential for the most part. Three main references are used to obtain cost correlations. The first, Perry's Chemical Engineers' Handbook [41] provides cost correlations for various components of chemical engineering processes in the following form:

$$
C=C_{0}\left(\frac{q}{q_{0}}\right)^{m},
$$

where $C_{0}$ and $q_{0}$ are the capital cost and the capacity of the reference component, respectively, whereas $q$ is the capacity of the component whose cost is unknown. The exponent $m$ expresses the deviation from the linear trend considering size effect on the equipment cost and is usually below unity. The above approach, known as exponential method, is the most common in engineering for fast cost estimations. The main drawback lies in the definition of just one reference point and one exponent. Errors in the estimation of these parameters lead to high deviation of the estimation costs especially for a component size far from the reference values.

For many components of interest in the ORC engine field, Seider et al. [42] represents another useful source of data for the design of chemical and synthesis processes, providing a detailed methodology for the calculation of equipment cost. Unlike Perry's approach, it does not present deviation issues for values far from references and accuracy is stated to be in the range of $\pm 25 \%$. The data used for these correlations were gathered in 2006 and the base cost functions are provided as logarithmic correlations of the form:

$$
C=\exp \left\{A_{0}+A_{1}[\ln (S)]+A_{2}[\ln (S)]^{2}+\cdots\right\},
$$

where $A_{i}$ are constants, and $S$ is the component's most important reference quantity (area for heat exchangers, volume flow rate for pumps, etc.). The equations are usually based on common construction materials such as carbon steel. For other materials, multiplying coefficients are provided.

Finally, the NETL (National Energy Technology Laboratory) report [43] is the result of work funded by the US government and it follows the approach of Seider for the estimation of base equipment cost. Data are provided as curves of capital cost against size for various components. In the present work, the correlations provided by Seider [42] are employed because of their more 
610 recent publication date, such that variations introduced by year-to-year conversion with the 611 Chemical Engineering Plant Cost Index (CEPCI) are minimised.

The previous references can be used for the estimation of the cost of the common components such as double-pipe heat exchangers, S\&T heat exchangers, generators and pumps. Unfortunately, there are few published studies on the cost of expanders. Among these, Astolfi [30] proposed a cost correlation for screw compressors, derived from the cost of more than 100 commercial compressors, consuming between 3.7 and $184 \mathrm{~kW}_{\mathrm{e}}$. This correlation, given below in Eq. (50), is a linear function of the volumetric flow rate at the exit of the machine, $\dot{V}_{\text {out }}$, expressed in $\mathrm{m}^{3} / \mathrm{s}$, this being the primary parameter that affects the size and the cost of these devices.

The cost correlations for each component are presented below.

\section{Centrifugal pump:}

The size factor $S$ is:

$$
S=15850 \dot{V}_{\text {pump }} \sqrt{3.28 H}
$$

where $\dot{V}_{\text {pump }}$ is the flow rate through the pump in $\mathrm{m}^{3} / \mathrm{s}$ and $H$ is the pump head in $\mathrm{m}$. The cost in

$$
C_{\text {pump }}=\exp \left\{9.72-0.602[\ln (S)]+0.0519[\ln (S)]^{2}\right\} \text {. }
$$

The cost of the electric motor that drives the pump is given in Eq. (47). This cost is added to the pump cost. The size parameter is the power absorbed by the pump in $\mathrm{kW}$.

$$
\begin{aligned}
C_{\text {motor }}=\exp \{ & 5.83+0.131\left[\ln \left(1.341 \dot{W}_{\text {pump }}\right)\right] \\
& +0.0533\left[\ln \left(1.341 \dot{W}_{\text {pump }}\right)\right]^{2} \\
& +0.0286\left[\ln \left(1.341 \dot{W}_{\text {pump }}\right)\right]^{3} \\
& \left.-0.00355\left[\ln \left(1.341 \dot{W}_{\text {pump }}\right)\right]^{4}\right\} .
\end{aligned}
$$

\section{Double-pipe heat exchangers:}

638 The cost correlation is based on carbon-steel heat exchanger, with the area $A$ in $\mathrm{m}^{2}$ :

$$
C_{\mathrm{B}, \mathrm{HE}}=\exp \{7.15+0.16[\ln (10.8 A)]\}
$$

641 The final purchase cost is determined from:

642

643

$$
C_{\mathrm{HE}}=F_{\mathrm{P}} F_{\mathrm{M}} C_{\mathrm{B}, \mathrm{HE}}, \text { where }
$$

$$
F_{\mathrm{P}}=0.851+0.129\left(\frac{p-101300}{41.4}\right)+0.0198\left(\frac{p-101300}{41.4}\right)^{2}
$$

645 where $F_{\mathrm{P}}$ is the pressure factor and the material factor, $F_{\mathrm{M}}$, is set to 2 for an outer pipe made of 
carbon steel and an inner pipe made of stainless steel.

Screw expander:

As screw compressors can be modified to operate in reverse mode as expanders, the correlation from Astolfi [30] is used. The size parameter is the volumetric flow rate at the end of the expansion in $\mathrm{m}^{3} / \mathrm{s}$ and the cost is expressed in $\$$.

$$
C_{\text {exp,scr }}=3144+217400 \dot{V}_{\text {out }},
$$

\section{Piston expander:}

A similar approach is taken to estimate the cost of reciprocating-piston expanders, again drawing on volumetric flow rate as the characteristic parameter for costing [44].

$$
C_{\text {exp,pis }}=1319+294500 \dot{V}_{\text {out }} \text {. }
$$

It is noted that the cost of the electric generator is not considered for either expander, since it is assumed that the expander would be mechanically connected to the generator of the CHP unit.

Finally, the costs of the pump, expander and heat exchangers are summed up to give an estimate of the power block cost $C_{\mathrm{PB}}$.

$$
C_{\mathrm{PB}}=C_{\mathrm{pump}}+C_{\mathrm{motor}}+C_{\mathrm{exp}}+C_{\mathrm{PH}}+C_{\mathrm{Ev}}+C_{\mathrm{DSh}}+C_{\mathrm{Cn}} .
$$

\section{Fluid selection}

The working fluid used in the ORC system directly impacts the safety, size, performance and costeffectiveness of the system. With the aim of narrowing down the vast list of possible fluids the following criteria are used:

$$
\text { - Global warming potential (GWP) } \leq 1430 \text { (R134a) }
$$

- Ozone depletion potential (ODP) $\leq 0.01$

- Health (NFPA) $\leq$ Moderate hazard (2)

- Instability (NFPA) $\leq$ low hazard (1)

According to those criteria, 18 fluids that meet the above requirements are considered in the simulations using the same boundary conditions and assumptions about the equipment. All necessary fluid properties are calculated from the NIST database using REFPROP 9.1. The environmental criteria eliminate the use of the chlorofluorocarbons and hydrochlorofluorocarbons, as they exhibit high ODPs and are being phased out [45]. Perfluorocarbons have no ODP, but are chemically very stable, resulting in very long ( $>1000$ years) lifetimes in the atmosphere due to the high numbers of carbon-fluorine bonds. Thus, they are also eliminated. The US NFPA (National Fire Protection Association) 704 standard is used to assess the fluids toxicity and stability. Assuming the maximum NFPA health hazard limit of 2 (moderate), fluids like carbon-disulphide and allyl-chloride are rejected as well. The 18 fluids analysed are listed along with their main properties in Tables 4 to 6 . They can be classified into alkanes, refrigerants, and others. 
Table 4: Main alkanes properties. $T_{\max }$ is the value reported by REFPROP and is representative of the decomposition temperature; $\mathrm{H}, \mathrm{F}$ and I are safety information indexes according to NFPA classification $(\mathrm{H}$, health; F, flammability; I, instability), with each index ranging from 0-no hazard to 4-maximum hazard; ODP is the ozone depletion potential index; and GWP is the global warming potential index.

\begin{tabular}{lccccccccc}
\hline Working fluid & $M(\mathrm{~kg} / \mathrm{kmol})$ & $T_{\text {crit }}\left({ }^{\circ} \mathrm{C}\right)$ & $p_{\text {crit }}($ bar $)$ & $T_{\max }\left({ }^{\circ} \mathrm{C}\right)$ & $\mathrm{H}$ & $\mathrm{F}$ & $\mathrm{I}$ & ODP & GWP \\
\hline Propane & 44 & 97 & 42 & 377 & 1 & 4 & 0 & 0 & \\
Butane & 58 & 152 & 38 & 302 & 1 & 4 & 0 & 0 & \\
Iso-pentane & 72 & 187 & 34 & 227 & 1 & 4 & 0 & 0 & \\
Pentane & 72 & 197 & 34 & 327 & 1 & 4 & 0 & 0 & \\
Iso-hexane & 86 & 225 & 30 & 277 & 2 & 3 & 0 & 0 & $4-6$ \\
Hexane & 86 & 235 & 30 & 327 & 2 & 4 & 0 & 0 & \\
Heptane & 100 & 267 & 27 & 327 & 1 & 3 & 0 & 0 & \\
Octane & 114 & 296 & 25 & 327 & 1 & 3 & 0 & 0 & \\
Cyclopentane & 70 & 239 & 46 & 277 & 1 & 3 & 0 & 0 & \\
Cyclohexane & 84 & 281 & 41 & 427 & 1 & 3 & 0 & 0 & \\
& & & & & & & & &
\end{tabular}

Table 5: Main properties of refrigerants. $T_{\max }$ is the value reported by REFPROP and is representative of the decomposition temperature; H, F and I are safety information indexes according to NFPA classification (H, health; F, flammability; I, instability), with each index 699

700

701

702

703

704

705

706

707

708

709

710

711

712

713

714

715

ranging from 0-no hazard to 4-maximum hazard; ODP is the ozone depletion potential index; and GWP is the global warming potential index.

\begin{tabular}{lccccccccc}
\hline $\begin{array}{l}\text { Working } \\
\text { fluid }\end{array}$ & $M(\mathrm{~kg} / \mathrm{kmol})$ & $\begin{array}{c}T_{\text {crit }} \\
\left({ }^{\circ} \mathrm{C}\right)\end{array}$ & $\begin{array}{c}p_{\text {crit }} \\
(\mathrm{bar})\end{array}$ & $\begin{array}{c}T_{\max } \\
\left({ }^{\circ} \mathrm{C}\right)\end{array}$ & $\mathrm{H}$ & $\mathrm{F}$ & $\mathrm{I}$ & ODP & GWP \\
\hline R1234yf & 114 & 95 & 34 & 137 & 1 & 4 & 0 & 0 & 4 \\
R134a & 102 & 101 & 41 & 182 & 1 & 0 & 1 & 0 & 1430 \\
R161 & 48 & 102 & 50 & 177 & 1 & 4 & 0 & 0 & 12 \\
R245fa & 134 & 154 & 36 & 167 & 2 & 1 & 0 & 0 & 1030 \\
R365mfc & 148 & 187 & 33 & 227 & 0 & 4 & 1 & 0 & 794 \\
\hline
\end{tabular}

Table 6: Main properties of other fluids considered. $T_{\max }$ is the value reported by REFPROP and is representative of the decomposition temperature; H, F and I are safety information indexes according to NFPA classification (H, health; F, flammability; I, instability), with each index ranging from 0-no hazard to 4-maximum hazard; ODP is the ozone depletion potential index; and GWP is the global warming potential index.

\begin{tabular}{lccccccccc}
\hline Working fluid & $M(\mathrm{~kg} / \mathrm{kmol})$ & $T_{\text {crit }}\left({ }^{\circ} \mathrm{C}\right)$ & $p_{\text {crit }}(\mathrm{bar})$ & $T_{\max }\left({ }^{\circ} \mathrm{C}\right)$ & $\mathrm{H}$ & $\mathrm{F}$ & $\mathrm{I}$ & $\mathrm{ODP}$ & $\mathrm{GWP}$ \\
\hline Acetone & 58 & 235 & 47 & 277 & 1 & 3 & 0 & 0 & $\mathrm{n} / \mathrm{a}$ \\
Toluene & 92 & 319 & 41 & 427 & 2 & 3 & 0 & - & 0 \\
Ethanol & 46 & 242 & 63 & 365 & 2 & 3 & 0 & 0 & $320-670$ \\
\hline
\end{tabular}

\section{System optimisation}

In the present work, two optimal configurations are studied, using different objective functions. The first considers the maximisation of the power output, for a pure thermodynamic optimisation; the second minimises the specific investment cost, for a thermoeconomic optimisation. Both screw and piston expanders are considered. As the heat source temperature is high, corresponding to large cycle pressure ratios, a two-stage screw expander is also analysed to help address the pressure ratio per stage limitations of screw expanders. The selected optimisation variables are: evaporating pressure, condensing pressure, degree of superheating 
and mass flow rate of the working fluid. The remaining properties of the cycle can be derived from those variables. The interior point algorithm is employed for the optimisation [46].

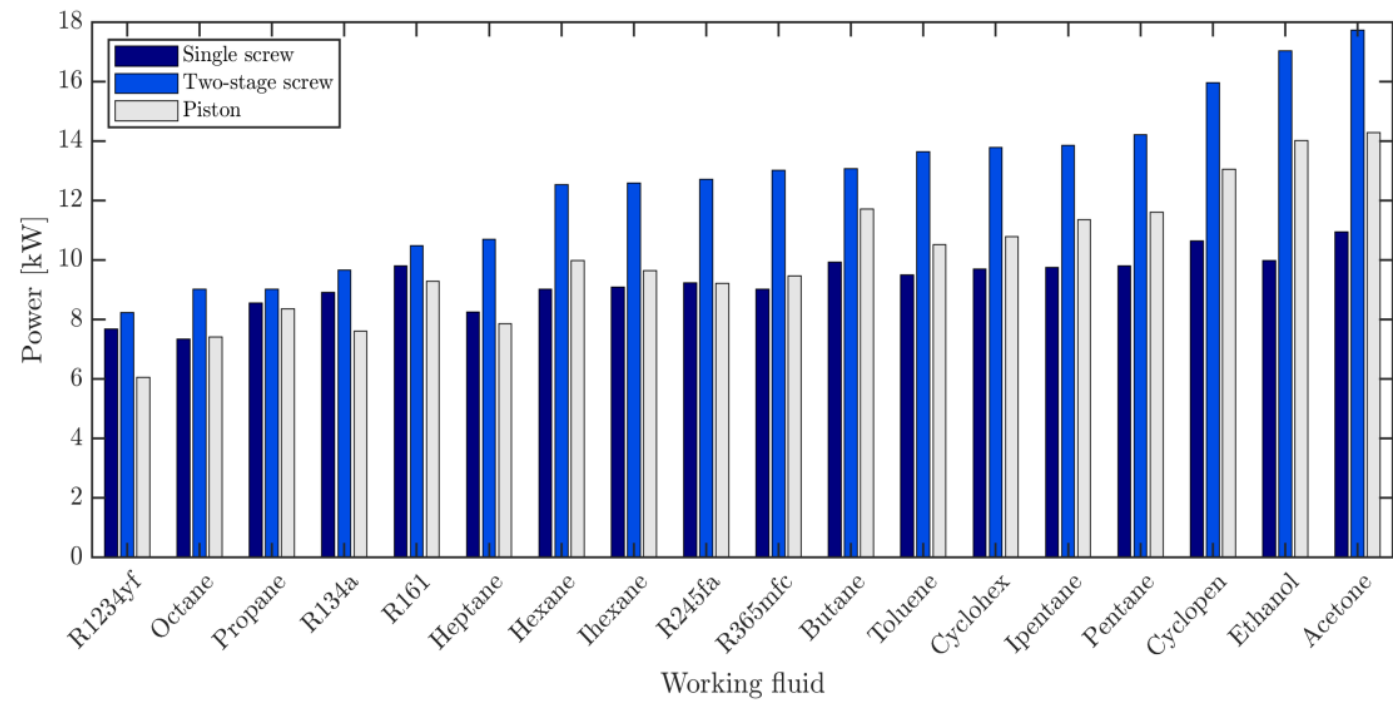

Figure 5: Comparison of maximum power outputs between single- and two-stage expanders using the 18 selected fluids. Each data point is obtained by optimising the ORC operating parameters ( $p_{\text {evap }}, p_{\text {cond }}, d_{\mathrm{SH}}$ and $\dot{m}_{\mathrm{wf}}$ ) so as to generate the maximum net power output, $\dot{W}_{\text {net. }}$.

\subsection{Thermodynamic optimisation}

The thermodynamic optimisation is designed to identify the ORC operating parameters $p_{\text {evap }}, p_{\text {cond, }}$ $d_{\mathrm{SH}}$ and $\dot{m}_{\mathrm{wf}}$ that maximise the net power output, $\dot{W}_{\text {net }}$ subject to the following constraints:

$$
\left\{\begin{array}{c}
p_{\text {cond }} \leq p_{\text {evap }} \leq 0.95 p_{\text {crit }} \\
0 \leq d_{\text {SH }} \leq 1 \\
\Delta T \geq 10^{\circ} \mathrm{C} \\
T_{\text {hs,out }} \geq 120^{\circ} \mathrm{C} \\
p_{\text {cond }} \geq 1 \text { bar }
\end{array}\right.
$$

The evaporator pressure is limited by the first constraint to keep the cycle subcritical, while the amount of superheating is controlled by the second. The temperature difference between the working fluid and the heat or sink source $(\Delta T)$ is always greater than $10{ }^{\circ} \mathrm{C}$. In addition, the outlet temperature of the exhaust gases remains above $120^{\circ} \mathrm{C}$, according to manufacturer requirements. The heat sink is cooling water, which enters the condenser at $20^{\circ} \mathrm{C}$, with the flow rate varying such that it exits at $30{ }^{\circ} \mathrm{C}$. The maximum temperature of the working fluid is limited according to the decomposition temperature provided by REFPROP. Finally, sub-atmospheric operation is prevented by imposing a lower limit for the condensing pressure of 1 bar.

The optimised power output obtained for each fluid and the three expanders configurations is shown in Figure 5. It shows that the best fluids are acetone and ethanol, except in the case of the single-stage screw expander for which cyclopentane provides slightly more power than ethanol. For most of the fluids there is a remarkable difference in terms of power output between singleand two-stage screw expanders. This is due to the dependency of the efficiency of the screw expander on the volume ratio. With the exception of fluids with very low critical temperature, the 
optimal volume ratio for the single-stage configuration is always slightly above 7 , as this is where the Astolfi correlation predicts a drop-off in efficiency.

Figure 6 shows the thermodynamic cycles of the ORC systems using acetone, R1234yf and octane as working fluid, which are representative of fluids with intermediate, low, and high critical temperature respectively, in combination with the three types of expanders. Using the two-stage expander, it is possible to increase the cycle pressure ratio, and achieve an improved temperature match with the heat source, and thus a higher power output. Similarly, for a given overall pressure ratio, by using two expanders it is possible to reduce the volume ratio across each expander, so increasing the isentropic efficiency and the power output [30]. Table 7 provides the power output and the optimal cycle parameters for the piston expander with acetone, R1234yf, and octane.

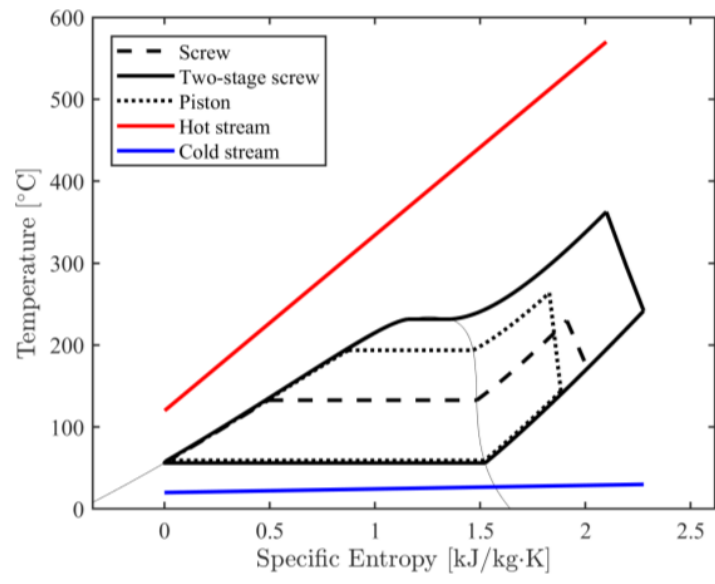

(a)

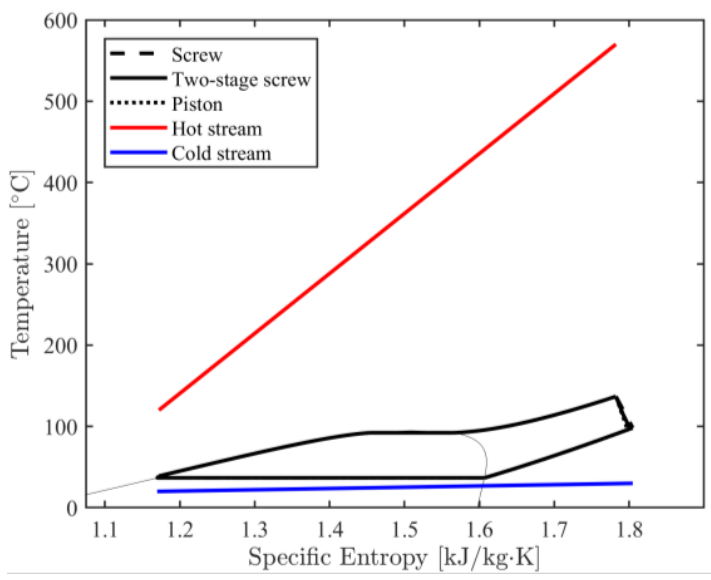

(b)

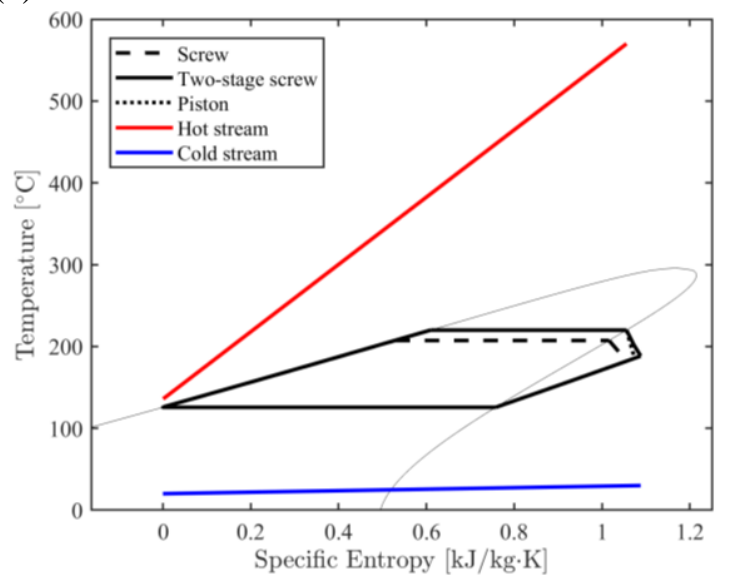

(c)

Figure 6: $T-s$ diagram for an ORC engine optimised for maximum net power with: (a) acetone, (b) R1234yf, and (c) octane as working fluids, with a screw expander (dashed line), piston expander (dotted line), and two-stage screw expander (solid line).

Fluids with very low critical temperatures, such as R1234yf, propane, R134a and R161, are seen to be poorly suited for the application considered in this work. Their critical temperatures range between 95 and $105{ }^{\circ} \mathrm{C}$ [32], which leads to poor matching with the heat-source temperature. The cycle pressure ratio is strongly constrained, and this leads to cycles with low exergy efficiency. For these fluids, the minimum approach temperature of $10{ }^{\circ} \mathrm{C}$ is achieved at the inlet 
of the condenser and the main exergy losses take place in the evaporator (see Figure 7). The high evaporating and condensing pressures (see Table 5 for R1234yf) are another reason for fluids with low critical temperature being unsuitable for this application, as these pressures call for thicker tubes in the heat exchangers, which are more expensive [42].

Table 7: Cycle parameters for an ORC engine optimised for maximum net power, with a piston expander with acetone, R1234yf, and octane.

\begin{tabular}{cccc}
\hline & Acetone & R1234yf & Octane \\
\hline$\dot{W}_{\text {net }}(\mathrm{kW})$ & 14.3 & 6.1 & 7.4 \\
$p_{\text {evap }}($ bar $)$ & 24.9 & 32.1 & 7.9 \\
$p_{\text {cond }}($ bar $)$ & 1.13 & 9.35 & 1.01 \\
$\dot{m}_{\text {wf }}(\mathrm{kg} / \mathrm{s})$ & 0.12 & 0.44 & 0.19 \\
$d_{\text {sh }}$ & 0.26 & 1.00 & 0.35 \\
$\eta_{\text {exp }}$ & 0.64 & 0.58 & 0.63 \\
$\eta_{\text {th }}$ & 0.15 & 0.06 & 0.08 \\
$\eta_{\text {ex }}$ & 0.29 & 0.12 & 0.15 \\
\hline
\end{tabular}

Organic fluids with very high critical temperature and molecular mass (such as octane), present a low power output for a very different reason to that for fluids with low critical temperature. These fluids, also called 'very dry' [47], are characterised by a small enthalpy drop in expansion (see Figure $6(\mathrm{c}))$ resulting in high temperature at the expander outlet. This leads to high exergy losses in the condenser since the condensing temperature is far from the sink temperature. However, this kind of fluids is characterised by the lowest exergy losses in the evaporator (see Figure 7) due to the possibility to reach a higher average temperature during the heating phase. In general, in this case the pinch point is located at the preheater inlet, as shown in Figure 7.
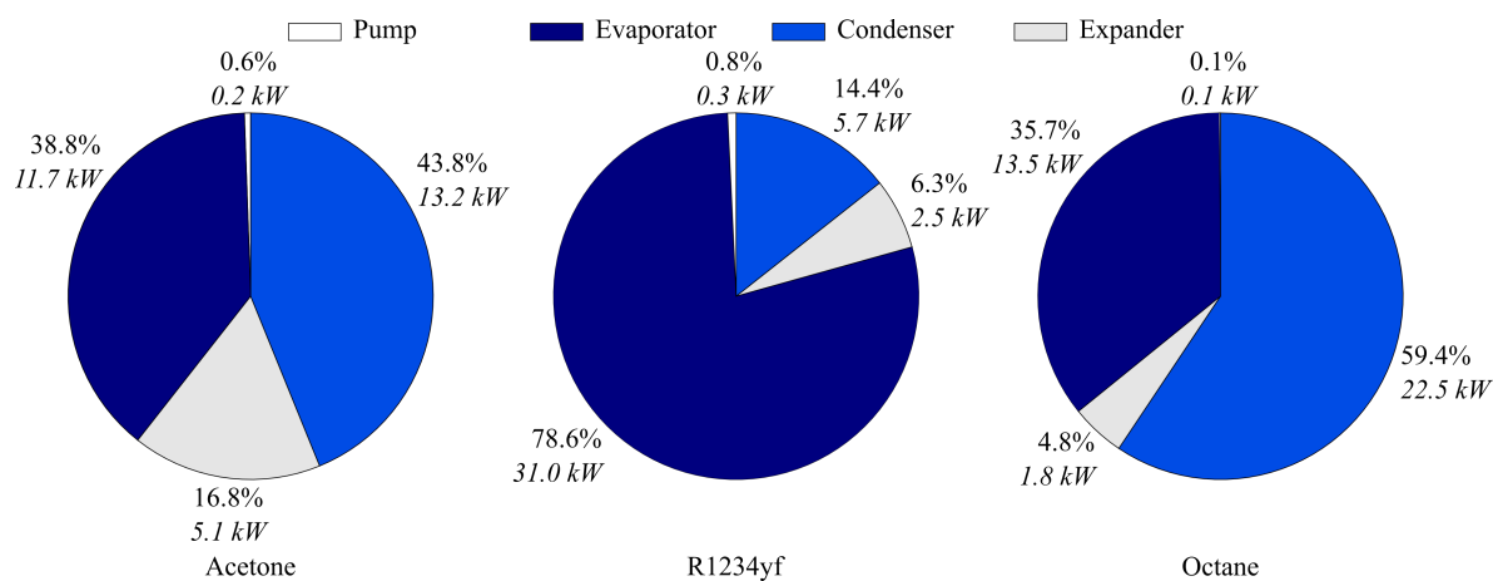

Figure 7: Distribution of exergy losses for an ORC engine optimised for maximum net power, with piston expander using acetone, R1234yf, and octane as working fluids.

Considering the above results, it appears that the best fluid is a compromise between exergy losses in the condenser and in the evaporator. Figure 8 provides the exergy losses in these two components and their sum, for each fluid. Acetone and ethanol, as previously seen, are the best ones, which is confirmed by the minimum overall losses in the heat exchangers. The exergy losses in the expander and in the pump are not displayed since they are of lesser magnitude. 


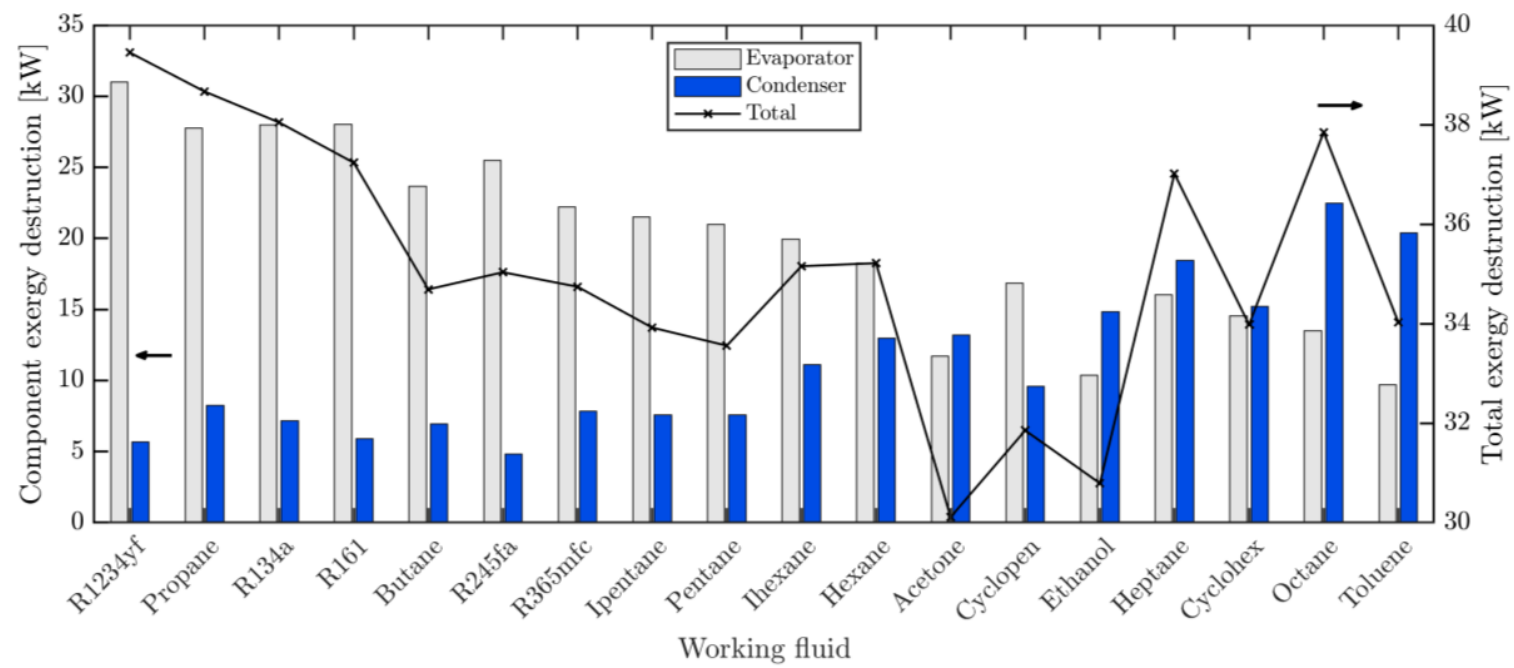

Figure 8: Exergy losses in the evaporator and in the condenser and their sum, for an ORC engine optimised for maximum net power.

\subsection{Thermoeconomic optimisation}

In this case, the objective function to be minimised is the turnkey specific investment cost:

$$
C_{\mathrm{s}}=\frac{C_{\mathrm{PB}}}{\dot{W}_{\mathrm{net}}},
$$

where $C_{\mathrm{PB}}$ is the power-block cost (see Table 9 for the detailed definition).

The same optimisation variables and constraints described in the previous section are employed for the thermoeconomic optimisation. Particular attention is paid to the design and cost analysis of the heat exchangers. The optimisation procedure is iterative: a first estimate of the diameters of the heat exchangers is provided (with nominal sizes); at the end of the optimisation cycle, a check on the velocity of the fluid through the tubes is performed; if the velocity does not satisfy the thresholds limits ( $<1.5 \mathrm{~m} / \mathrm{s}$ for liquid; $<30 \mathrm{~m} / \mathrm{s}$ for vapour) the diameters are increased and a new optimisation cycle is started. The iterative procedure is repeated until the constraints on the fluid velocity are satisfied.

When minimising the specific investment cost (as reported in Table 8) with acetone as working fluid, the two-stage screw expander is found to give significantly greater net power output $(14.2 \mathrm{~kW})$ compared to either the piston expander $(10.5 \mathrm{~kW})$ or the single-stage screw expander $(10.1 \mathrm{~kW})$. This is because of the higher overall pressure ratio of 12.8 which can be achieved by two screw expanders in series. The single-stage piston expander operates at a higher pressure ratio of 9.5 relative to the single-stage screw expander, which operates at a pressure ratio of 7.2. 
824 Table 8: Thermodynamic parameters of the ORC system with acetone as working fluid as resulting 825 from: (i) the maximum power; and (ii) minimum specific investment cost optimisation.

\begin{tabular}{ccccccc}
\hline & \multicolumn{2}{c}{ Screw expander } & \multicolumn{2}{c}{ Piston expander } & \multicolumn{2}{c}{$\begin{array}{c}\text { Two-stage screw } \\
\text { expander }\end{array}$} \\
\hline & $\begin{array}{c}\text { Opt. max } \\
\text { power }\end{array}$ & $\begin{array}{c}\text { Opt. min. } \\
\text { spec. cost. }\end{array}$ & $\begin{array}{c}\text { Opt. max } \\
\text { power }\end{array}$ & $\begin{array}{c}\text { Opt. min. } \\
\text { spec. cost. }\end{array}$ & $\begin{array}{c}\text { Opt. max } \\
\text { power }\end{array}$ & $\begin{array}{c}\text { Opt. min. } \\
\text { spec. cost. }\end{array}$ \\
\hline$C_{\mathrm{s}}($ Eur $/ \mathrm{kW})$ & 3130 & 2370 & 2430 & 1630 & 2190 & 1990 \\
$\dot{W}_{\text {net }}(\mathrm{kW})$ & 10.9 & 10.1 & 14.3 & 10.5 & 17.7 & 14.2 \\
$p_{\text {evap }}(\mathrm{bar})$ & 8.0 & 29.0 & 24.9 & 44.6 & 44.6 & 44.6 \\
$p_{\text {cond }}(\mathrm{bar})$ & 1.01 & 4.00 & 1.13 & 4.71 & 1.01 & 3.50 \\
$\dot{m}_{\mathrm{wf}}(\mathrm{kg} / \mathrm{s})$ & 0.13 & 0.12 & 0.12 & 0.09 & 0.10 & 0.12 \\
$d_{\mathrm{sh}}$ & 0.29 & 0.38 & 0.26 & 1.00 & 0.56 & 0.45 \\
$\eta_{\text {th }}$ & 0.11 & 0.11 & 0.15 & 0.11 & 0.18 & 0.15 \\
$\eta_{\mathrm{ex}}$ & 0.22 & 0.21 & 0.29 & 0.22 & 0.36 & 0.29 \\
\hline
\end{tabular}

826

827

828

829

830

831

832

833

834

835

836

837

838

839

840

841

842

843

844

845

846

847

848

849

850

851

852

853

854 855
In order to compare the results from both thermodynamic and thermoeconomic optimisations, Table 8 provides the specific costs and main thermodynamic parameters for the ORC engine using acetone and the three expander configurations. The ORC engine designs identified by the two optimisations differ quite strongly. For the system with a single-stage screw expander, switching from thermodynamic to thermoeconomic optimisation reduces the specific cost by $24.7 \%$, while it falls by only by $8.7 \%$ for the two-stage expander. As the expander is the most expensive component, the thermoeconomic optimisation leads to increases in both the condensing and evaporating pressures, which reduce the volumetric flow rate and consequently the expander cost. For this reason, the single-stage expander has a larger margin of improvement in comparison to the two-stage one. Moreover, the average temperature of the heating phase is increased. Consequently, the thermoeconomic optimisation produces only a slight reduction in the power output, but a significant reduction in the investment cost. In most cases, the increase of the power output from moving from a single-stage to a two-stage expander is sufficient to overcome the increase in investment cost, leading to a more cost-effective system overall, as shown in Figure 9. Fluids with very low critical temperatures (propane, octane, R1234yf, R161 and R134a) are the exception for the same reasons as previously explained. In fact, for these fluids, the optimal cycle parameters remain largely unchanged and the slight increase of the power output is not sufficient to compensate for the additional cost of the second expander stage.

Table 8 shows that, for acetone, the piston expander represents the solution with the minimum specific cost. Both evaporating and condensing pressures are increased with respect to the maximum power optimisation results; this leads to a reduction of the mass flow rate and of the expansion ratio. As a consequence, both the power output and the investment cost decrease, with a stronger reduction in the latter leading to a lower specific investment cost. Similar behaviour is obtained for most of the considered fluids, as demonstrated by the specific costs reported in Table 8 . The exceptions are fluids such as octane, heptane, toluene, R245fa, R365mfc, and R1234vf, which have low critical pressures that restrict the scope for higher pressure operation. The most suitable fluids for the considered application are found to be acetone and ethanol in conjunction with a piston expander. 


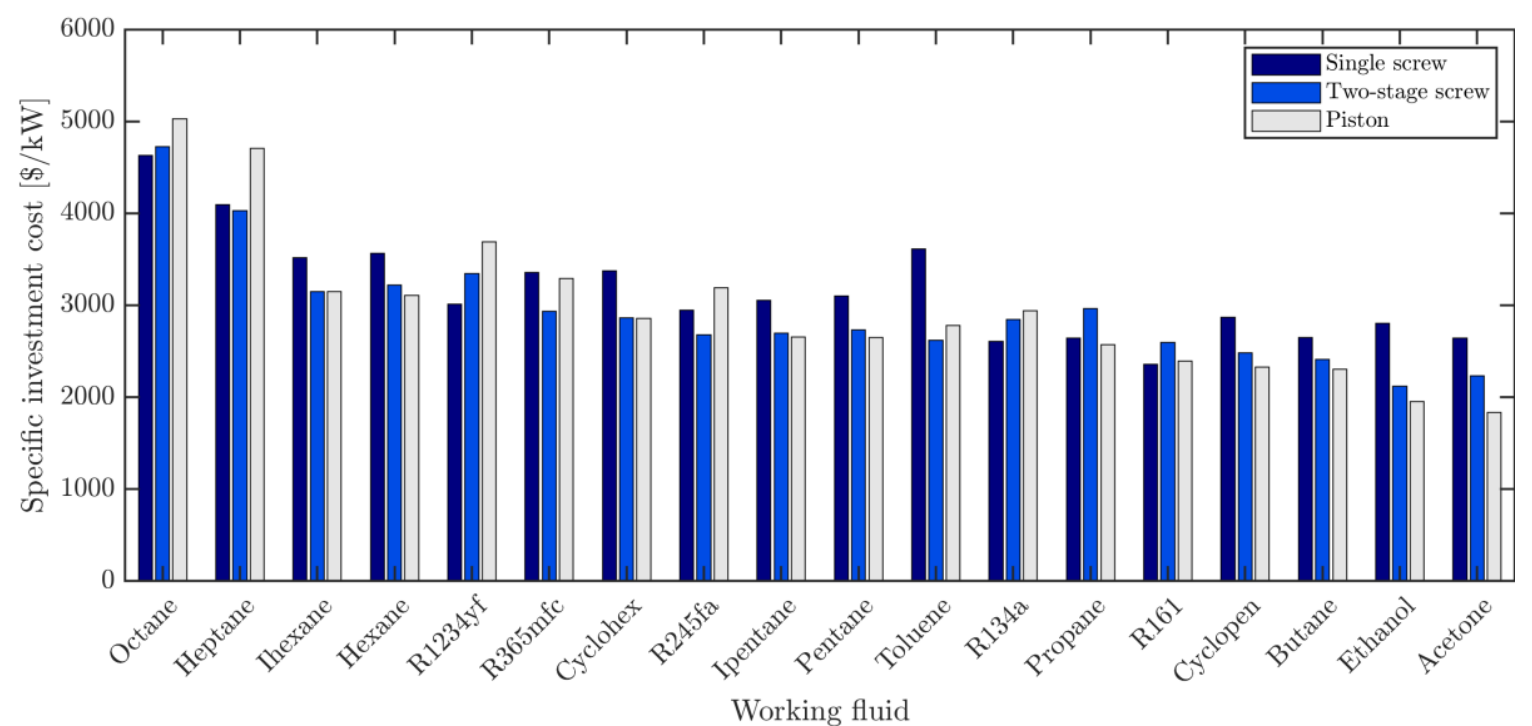

Figure 9: Comparison of specific investment costs for different working fluids. Specific costminimisation ORC engine optimisation.

Figure 10 provides the distribution of exergy losses for three systems optimised with a piston expander, with acetone, R1234yf, and octane, respectively. High critical-temperature fluids like octane are shown to be unsuitable for multiple reasons. Much of the potential for useful work contained in the exhaust gases is destroyed since the condensing temperature is very high, inducing excessive exergy losses in the condenser. R1234yf, as discussed in the previous section, shows the opposite problem, with high losses in the evaporator as a consequence of the low critical temperature. It is noteworthy that the distributions of exergy losses obtained for R1234yf and octane with the present thermoeconomic optimisation, under the considered constraints, are very similar to those obtained with the previous thermodynamic optimisation, as shown in Figure 7, as the cycles are heavily constrained. For acetone, the shift to higher evaporating and condensing pressures means that the system optimised for minimum cost shows higher exergy losses in the condenser than are seen in the system optimised for maximum power.

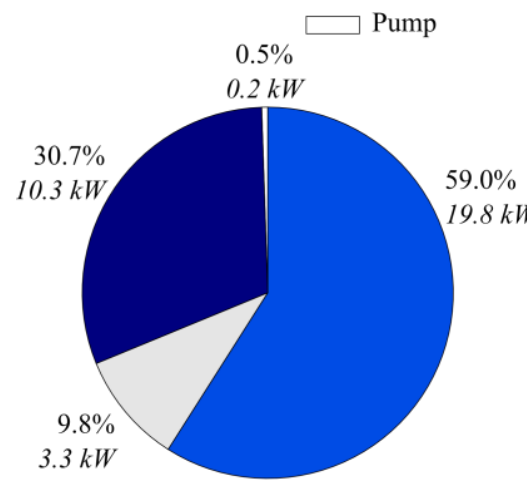

Acetone

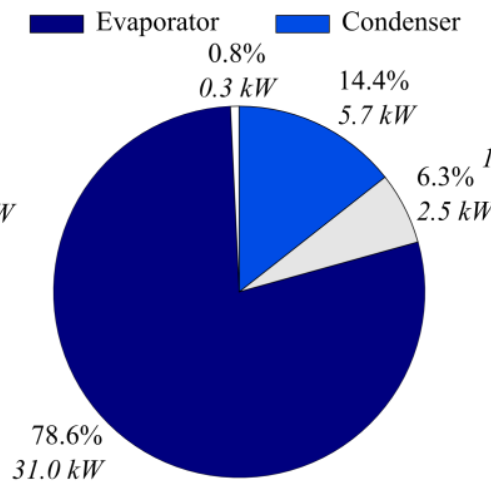

R1234yf

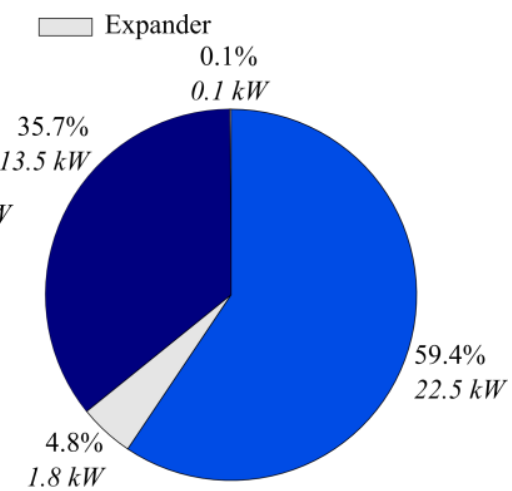

Octane

Figure 10: Distribution of exergy losses for the cycle with piston expander using acetone, R1234yf, and octane as working fluid, after thermoeconomic optimisation. 


\section{Economic analysis}

This section provides a technoeconomic feasibility assessment of the ORC systems investigated earlier, using acetone as the working fluid. Screw and piston expanders, and the minimum-cost versus maximum-power scenarios are compared. The cost assessments of the ORC systems include operation and maintenance costs taken from the literature. The investment profitability is evaluated by means of the net present value (NPV) and the internal rate of return (IRR), while the levelised cost of energy (LCOE) is calculated to allow comparisons of the electricity generation costs with other technologies. The sensitivity of the economic indices to the electricity selling price (or avoided purchase cost in case of onsite consumption) and the alternative use of the available heat from the ICE for cogeneration are also assessed. The profitability of these WHR solutions is strongly influenced by the electricity selling price and by the alternative option to use the waste heat from the ICE to match the onsite heat demand. As highlighted in Refs. [27,48], a fair evaluation of the profitability of ORC-based WHR systems at the premises of end users should take into account the energy demand profile and the cost of energy supply. The purpose of this sensitivity analysis is to establish the conditions of heat-demand intensity, costs of heat supply and avoided cost of electricity at which a WHR ORC system becomes profitable in this application.

\subsection{Economic model}

The power-block cost $C_{\mathrm{PB}}$ assumed in this analysis includes the cost of site preparation and the cost of service facilities in addition to the purchased equipment cost. Table 9 provides a summary of the cost components to estimate the total investment cost (adapted from Seider et al. [42]).

Table 9: Components of total investment cost.

\begin{tabular}{ll}
\hline Power-block cost, $C_{\mathrm{PB}}$ & $C_{\mathrm{PB}}=\sum_{i \in \text { Components }} C_{i}$ \\
Cost of site preparation, $C_{\text {site }}$ & $C_{\text {site }}=0.04 \cdot C_{\mathrm{PB}}$ \\
Cost of service facilities, $C_{\text {serv }}$ & $C_{\text {serv }}=0.04 \cdot C_{\mathrm{PB}}$ \\
Total direct permanent investment, $C_{\mathrm{DPI}}$ & $C_{\mathrm{DPI}}=C_{\mathrm{PB}}+C_{\text {site }}+C_{\text {serv }}$ \\
Cost of contingencies and contractors' fees, $C_{\text {cont }}$ & $C_{\text {cont }}=0.10 \cdot C_{\mathrm{DPI}}$ \\
Cost of land, $C_{\text {land }}$ & $C_{\text {land }}=0$ \\
Cost of royalties, $C_{\text {royal }}$ & $C_{\text {royal }}=0$ \\
Cost of plant startup, $C_{\text {startup }}$ & $C_{\text {startup }}=0.10 \cdot C_{D P I}$ \\
Total investment cost, $C_{\mathrm{TCI}}$ & $C_{\mathrm{TCI}}=C_{\mathrm{DPI}}+C_{\text {land }}+C_{\text {royal }}+C_{\text {startup }}$ \\
\hline
\end{tabular}

903

904

905

906

907

908

909

910

911

912

913

The power-block cost, $C_{\mathrm{PB}}$, is calculated via the component-cost equations listed in Section 3. Contingency costs and contractors' fees incurred during the construction of the system are set to $10 \%$ of the direct permanent investment, $C_{\mathrm{DPI}}$. The cost of the land, $C_{\text {land, }}$ is set to zero, under the assumption that the bottoming ORC system is being integrated into an existing CHP facility. The cost of royalties is also set to zero. Assuming the generated power from the ORC system is used to meet the local electricity demand, the annual income corresponds to the reduction of the end user's energy bill.

Mean electricity prices for industrial consumers in European countries from 2014 to 2016, shown in Figure 11, are used to define a suitable range of electricity prices for a sensitivity analysis of the economic viability. The lowest limit of $0.06 € / \mathrm{kWh}$ is representative of countries such as Bulgaria, Finland and Sweden, while the upper limit of $0.18 € / \mathrm{kWh}$ is representative of countries with high 
914 electricity prices, such as Cyprus, Germany, Italy, Malta and the UK. It should be noted that the 915 electricity price is the relevant benchmark only where any onsite generation, such as a gas-fired ICE, 916 is unable to increase output further to meet the demand for electricity; otherwise the comparison 917 should be made against the cost of additional gas consumed to run the ICE at higher output.

918

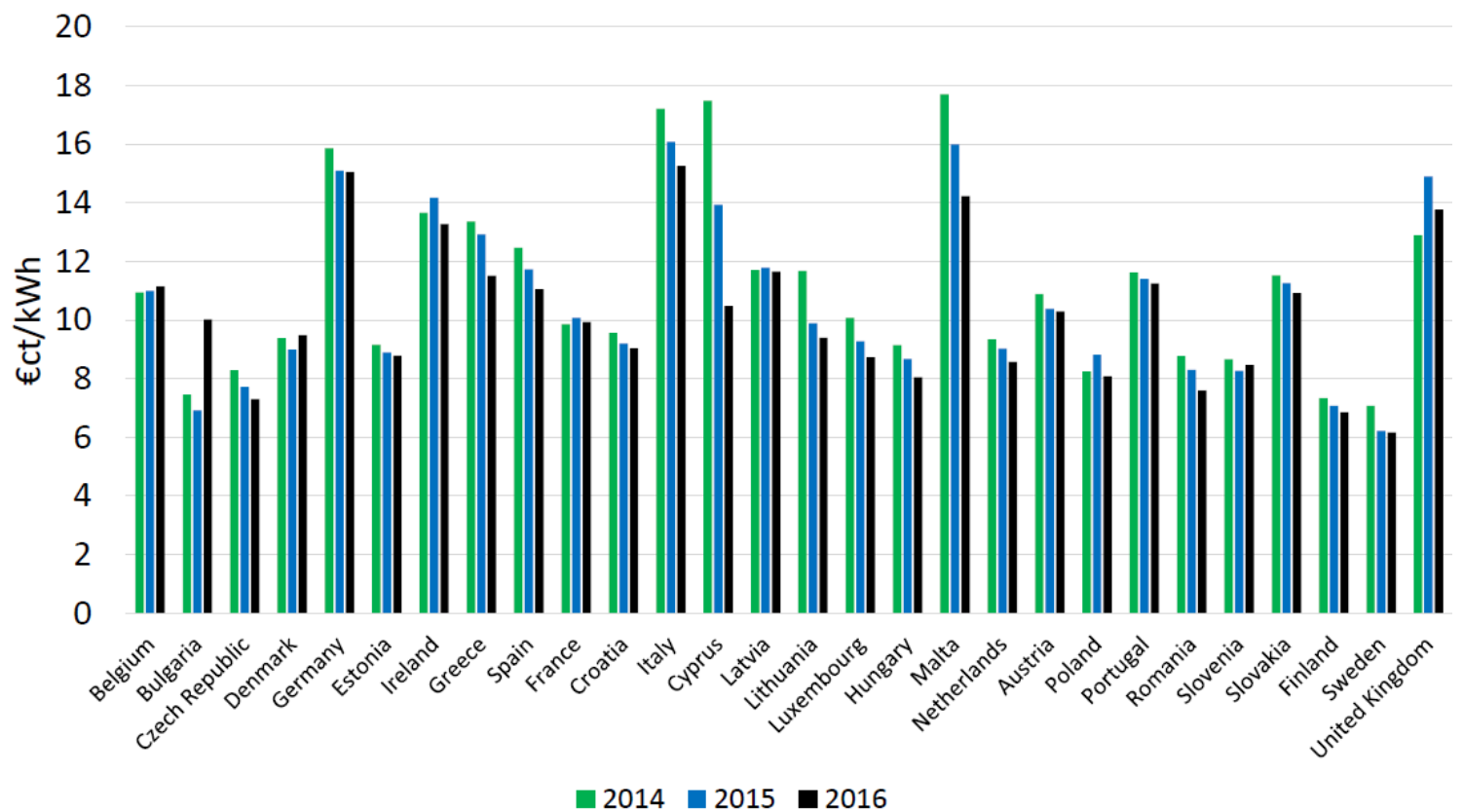

Figure 11: Electricity prices for industrial consumers in European countries 2014-2016 [49].

The financial parameters for the calculation of the economic indices are reported in Table 10. The operation and maintenance costs and the insurance costs are set to $5 \%$ and $0.3 \%$ of the $C_{\text {TCI. }}$

Table 10: Assumptions used in the financial model.

\begin{tabular}{ll}
\hline Plant lifetime & 20 years \\
Load factor, $f_{\text {load }}$ & $0.90(7884 \mathrm{~h} /$ year $)$ \\
System degradation rate, $f_{\text {degr }}$ & $1.0 \%$ \\
Cost of capital, $c_{\mathrm{c}}$ & $5.0 \%$ \\
Inflation rate, $r_{\mathrm{i}}$ & $2.0 \%$ \\
Nominal discount rate, $k=\left(1+c_{\mathrm{c}}\right) \cdot\left(1+r_{\mathrm{i}}\right)$ & $7.1 \%$ \\
Inflation rate of electricity price, $e$ & $2.0 \%$ \\
\hline
\end{tabular}

926

927

928

929

930 931
The annual income from electricity production of the ORC system assumes a full-load capacity factor of $90 \%$ (i.e., 7884 operating h/year), which is representative of a CHP engine in baseload operation. The annual energy production is calculated assuming the installed power from Table 8 for the different expanders and objective functions. The following economic indices are evaluated: 
934

935

936

937

938

939

940

941

942

943

944

945

946

947

948

949

950

951

952

953

954

955

956

957

958

959

960

961

962

963

964

965

966

967

$$
\begin{aligned}
\mathrm{NPV} & =\sum_{i=1}^{N} \frac{C F_{i}}{(1+k)^{i}}-C_{\mathrm{TCI}} \\
& =\sum_{i=1}^{N}\left[\frac{A E P_{0} \cdot\left(1-f_{\mathrm{degr}}\right)^{i} \cdot C_{\text {elect }}(1+e)^{i}-C_{\text {annual }, i}}{(1+k)^{i}}\right]-C_{\mathrm{TCI}},
\end{aligned}
$$

where $A E P_{0}$ represents the annual electricity production in the first year, $i$ is the time period (year), and $N$ the plant lifetime (20 years). $C F_{\mathrm{i}}$, the net cash flow for year $i$, considers the net cash flow derived from the electricity savings minus the annual costs, sum of operation, maintenance and insurance costs. $C_{\text {elect }}$ represents the electricity avoided cost or selling price, and $C_{\text {annual,i }}$ is the operation and maintenance annual cost.

\section{Levelised cost of electricity ( $L C O E)$ :}

The LCOE is the cost incurred to generate a given amount of electricity, including operational and annualised investment costs. In the proposed application, it represents the minimum electricity supply cost to secure the investment profitability, and is defined as follows:

$$
\mathrm{LCOE}=\frac{C_{\mathrm{TPI}}+\sum_{i=1}^{N} C_{\mathrm{annual}, i}}{\sum_{i=1}^{N} \frac{A E P_{0} \cdot\left(1-f_{\mathrm{degr}}\right)^{i}}{(1+k)^{i}}}
$$

In Eq. (57), the annual operating costs, $C_{\text {annual,i, }}$, are kept constant during the system lifetime and not discounted, while the electricity generation is discounted [50]. The rationale is that the energy generated corresponds to the earnings from the sale of this energy.

\subsection{Economic findings}

Assuming acetone as the working fluid, and considering two objective functions (maximum power and minimum specific cost), the six system configurations of Table 8 are obtained. The corresponding total investment costs are calculated on the basis of the cost factors of Table 9. Figure 12 reports the LCOE for these scenarios, and Figure 13 reports the NPV and IRR when varying the electricity avoided cost in the range $0.07-0.19 € / \mathrm{kWh}$.

In particular, Figure 12 shows the levelised cost of electricity (LCOE) as a function of the lifetime (neglecting repowering costs). The gradient of the LCOE curve flattens over time, and the LCOE at 15 years approaches that at 20 years of lifetime. As expected, the cost minimisation strategy produces a lower LCOE relative to the maximum power optimisation. Moreover, the piston expander presents lower LCOE in comparison to the screw expander when the minimum cost strategy is considered, due to its lower investment cost. However, if the optimisation is carried out to maximise power, the two-stage screw expander offers the lowest LCOE, due to its higher conversion efficiency. 


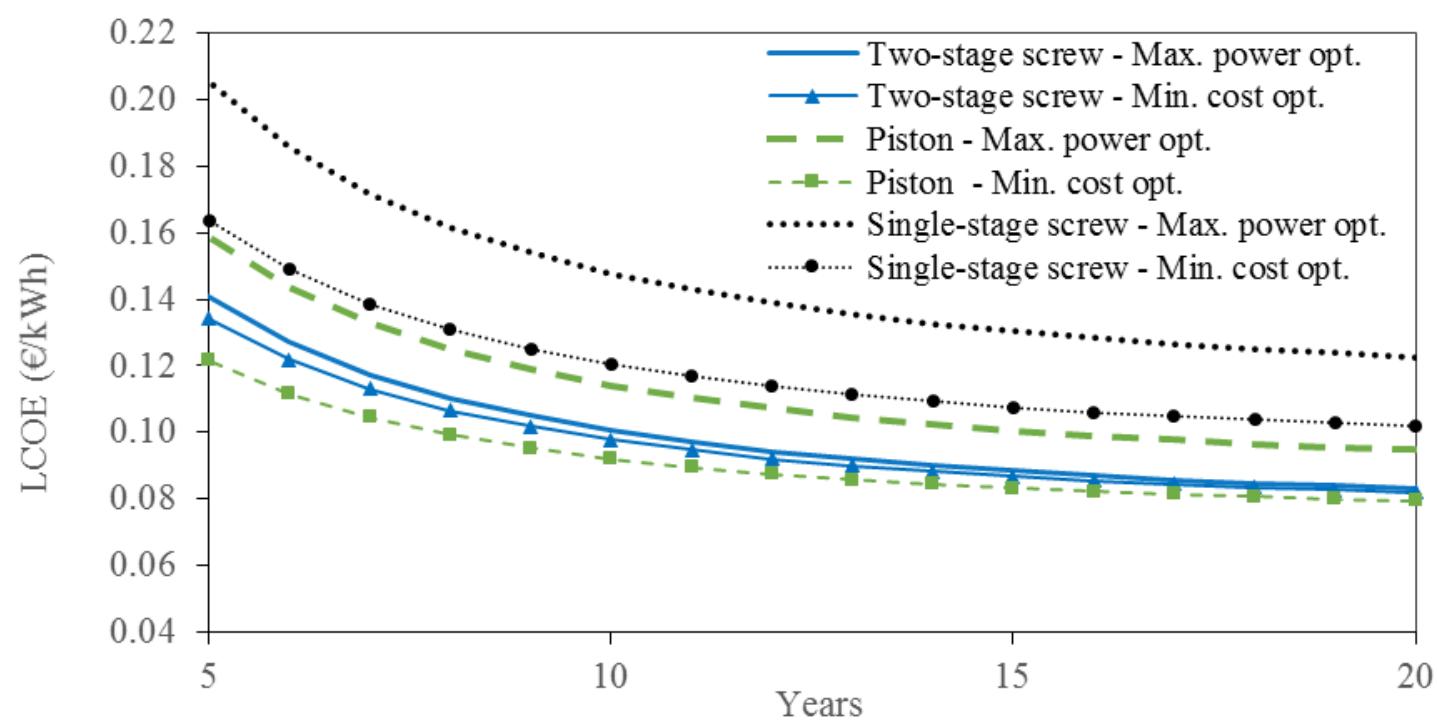

Figure 12: Variation of LCOE over the lifetime with acetone as working fluid and for a poweronly scenario (i.e., no heat demand). Results are reported for the two objective functions: maximising net power and minimising specific investment cost.

Figure 13 shows discounted payback times (PBT) ranging between a minimum value of 2 years (piston expander optimised for minimum investment cost in the high electricity-value scenario), to values beyond the investment lifetime (negative NPV), (i.e. single-stage screw expander optimised for maximum power in the low electricity value scenario). The annual cash flow remains relatively constant over time because the degradation rate of the system and the rate of inflation of the electricity price are of comparable magnitude.

980 These results indicate that the most influential factor in the profitability of WHR via small-scale ORC systems is the value of produced electricity. In particular, ORC systems already appear to be economically viable for countries where the industrial electricity price is above $0.13 \$ / \mathrm{kWh}$ such as Italy, Germany and United Kingdom. In contrast, for countries with low electricity prices such as Sweden, Finland and Bulgaria are unlikely to be considered economically viable. In the high electricity value scenario, the two-stage screw expander optimised for maximum power offers the highest NPV; however, this is not reflected on the IRR, which is highest when selecting the piston expander optimised for minimum cost, due to the reduced capital cost. At low electricity prices, the cheapest option of the piston expander with minimum cost optimisation delivers both the highest NPV and the highest IRR and, due to its lower investment cost, and it also offers the best 991 


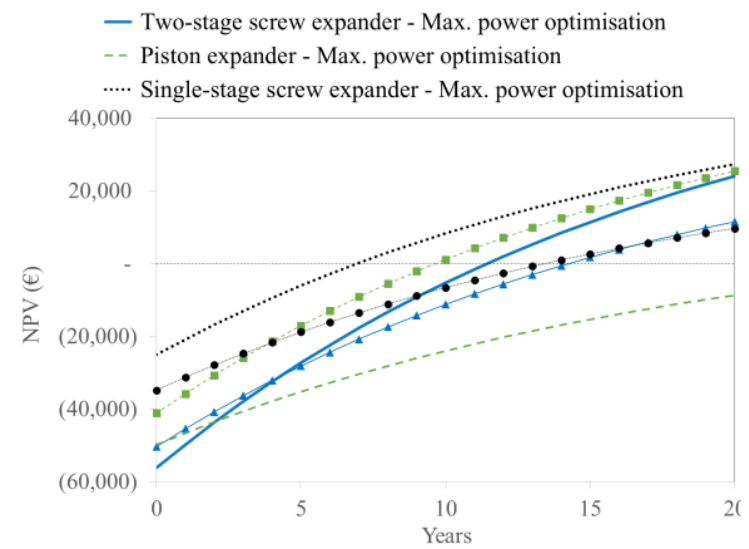

(a) NPV, $C_{\text {el }}=0.07 € / \mathrm{kWh}$

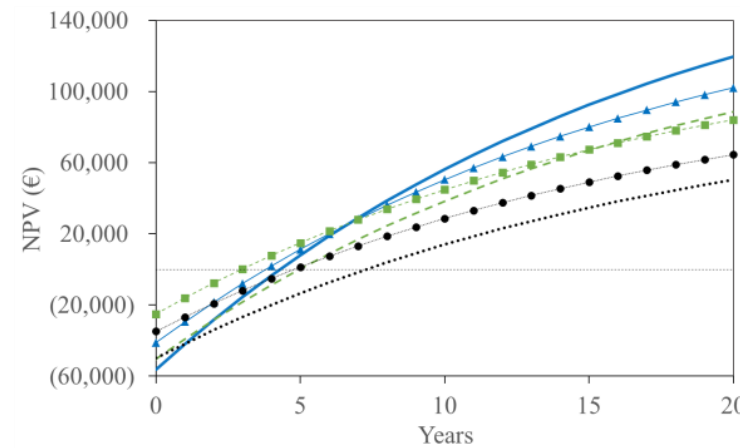

(c) NPV, $C_{\text {el }}=0.13 € / \mathrm{kWh}$

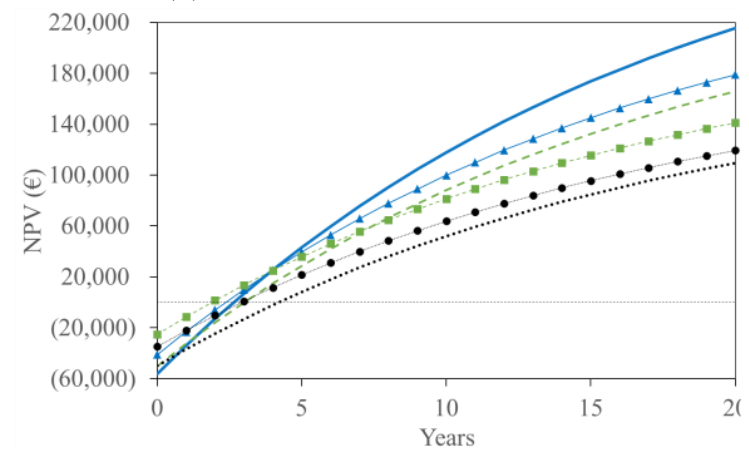

(e) NPV, $C_{\text {el }}=0.19 € / \mathrm{kWh}$

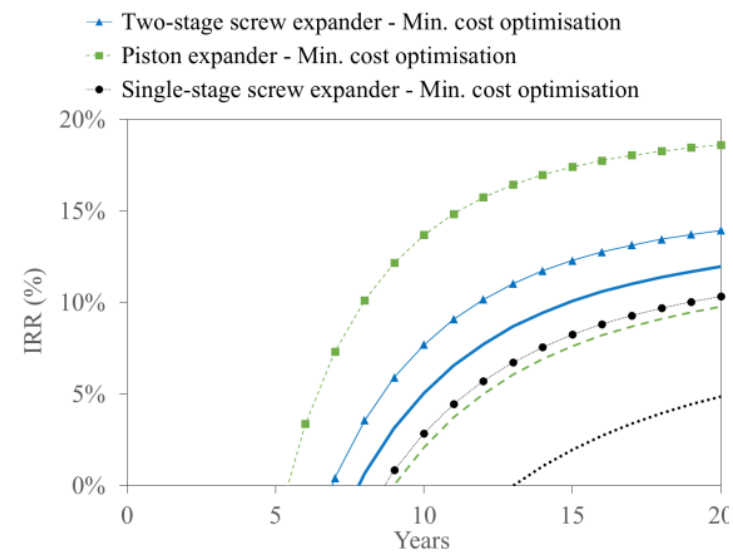

(b) IRR, $C_{\text {el }}=0.07 € / \mathrm{kWh}$

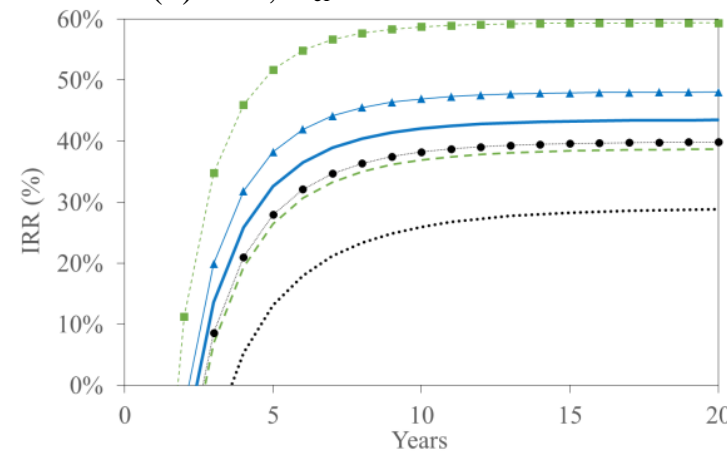

(d) IRR, $C_{\text {el }}=0.13 € / \mathrm{kWh}$

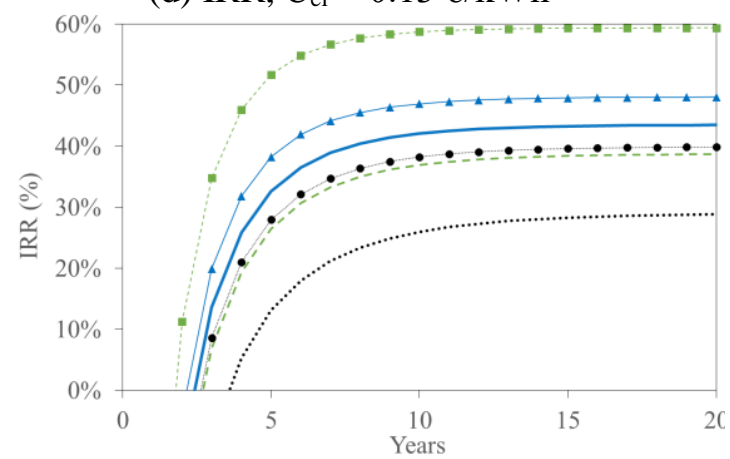

(f) IRR, $C_{\text {el }}=0.19 € / \mathrm{kWh}$

992 Figure 13: Variation of NPV and IRR over a 20-year plant life for a power-only scenario (i.e., 993 no heat demand) for a range of avoided electricity costs $\left(C_{\mathrm{el}}\right)$. Systems with reciprocating-piston, 994 single- and two-stage screw expanders are optimised for maximum net power output and 995 minimum specific investment cost in turn.

One of the main barriers when installing bottoming ORC engines coupled to internal combustion engines for decentralised generation is the competing use of such heat to match onsite heating demand at medium-high temperature. This is because the ORC engine discharges heat from the condenser at low temperature, not compatible with the temperature of the heat demand. The two available alternatives are to switch on/off the ORC engine, on the basis of the heat demand profile, or install an additional heating system to cover the demand. The option to vary the condensing temperature of the ORC engine in order to match the variable heating demand of the load has also been explored by some manufacturers, while the trade-off between condensing 
temperature and electrical efficiency has been investigated in the literature, in order to maximise the global energy efficiency of the system (thermal and electrical) [51].

The influence of heat demand on the LCOE and NPV of the ORC system is illustrated in Figures 14 and 15 , considering the ORC system to be operating as baseload, and incurring additional costs for natural gas consumption to match the heating demand when required. These costs are incorporated as operating costs of the ORC generator, to allow for a fair comparison of the profitability of such waste-heat recovery system with or without the presence of onsite heat demand. As can be seen from Figure 14, the LCOE for the minimum cost system with a piston expander increases from $0.05 € / \mathrm{kWh}_{\mathrm{e}}$ (no heat demand) to 0.07 and $0.08 € / \mathrm{kWh}_{\mathrm{e}}$ respectively for the scenario of $30 \%$ and $50 \%$ heat-demand intensity.

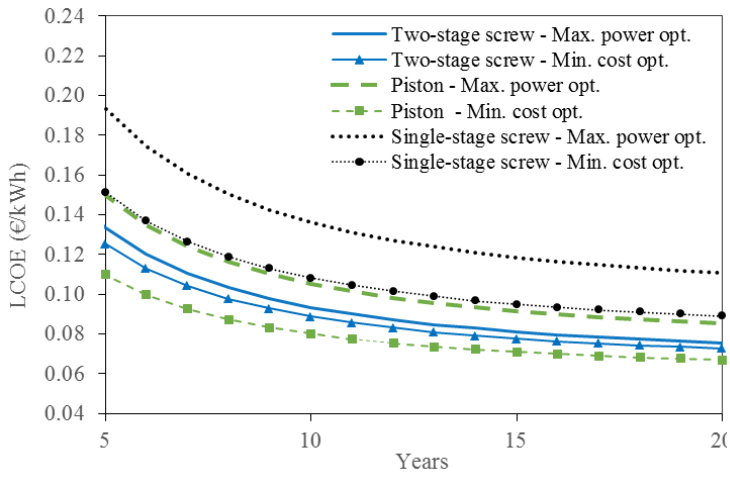

(a)

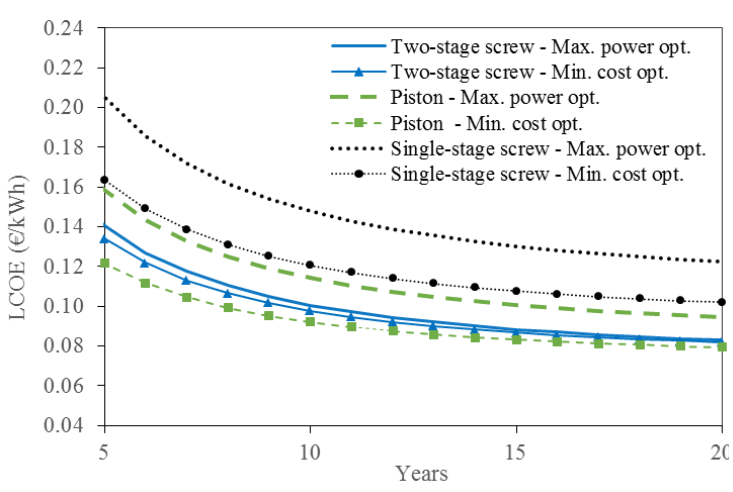

(b)

1017 Figure 14. Variation of LCOE over the lifetime assuming heat demand respectively of: (a) 30\%, and (b) $50 \%$ of the bottoming ORC engine operating time, at a heating cost of $0.03 € / \mathrm{kWh}$, for the six expander and optimisation scenarios, and acetone as the working fluid.

The effect on the project economics of burning natural gas to replace heat supplied to the ORC engine can be seen in Figure 15. At low avoided electricity costs, the payback time is seen to lengthen substantially for the case of $30 \%$ heat demand and almost all of the systems fail to achieve a positive NPV in the $50 \%$ heat demand case. Depending on the profile of heat demand, it is likely that turning the ORC off when heat is required locally would be preferable, though the project economics for the ORC would still be negatively affected.

For higher avoided electricity costs, it becomes more feasible to cover the cost of natural gas consumption through savings associated with the ORC electricity generation, though this does not offset the associated emissions. The shortest payback time of $2-4$ years is achieved with the piston expander system optimised for minimum cost, for avoided costs of electricity of 0.19 $0.13 € / \mathrm{kWh}$, respectively. The system with a two-stage screw expander optimised for maximum power remains the most profitable over the project lifetime. 

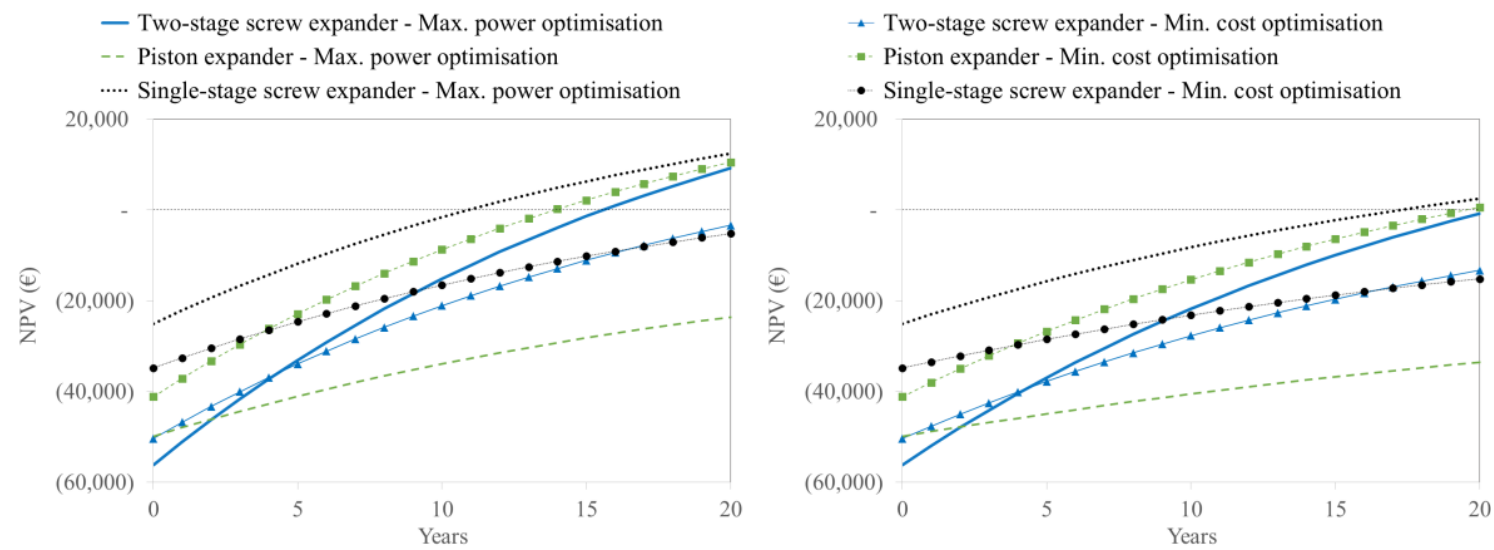

(a) $C_{\mathrm{el}}=0.07 € / \mathrm{kWh}, 30 \%$ heat demand

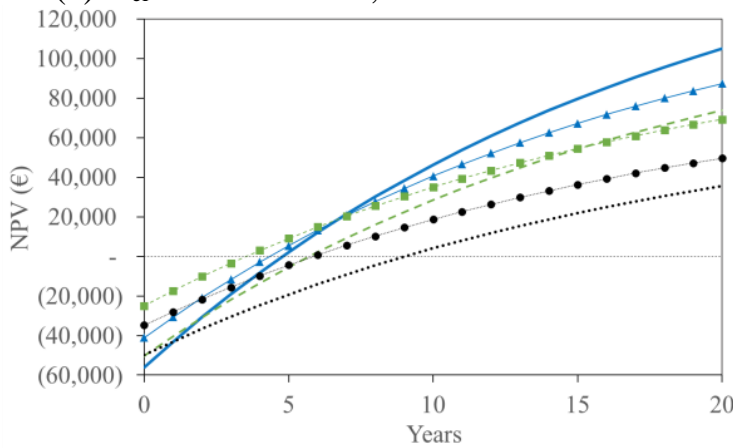

(b) $C_{\mathrm{el}}=0.07 € / \mathrm{kWh}, 50 \%$ heat demand

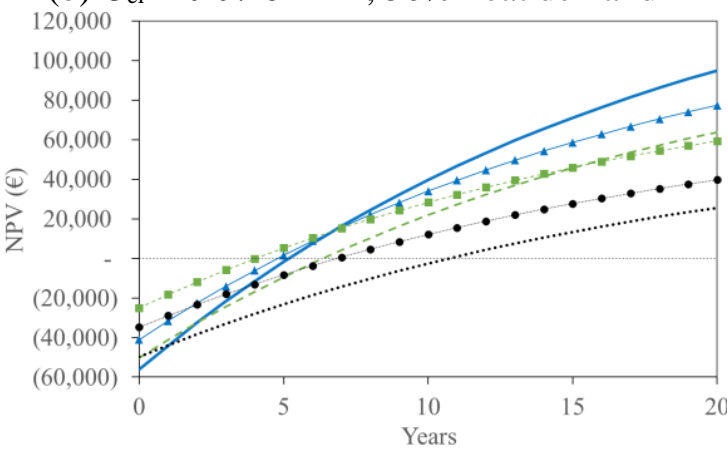

(c) $C_{\mathrm{el}}=0.13 € / \mathrm{kWh}, 30 \%$ heat demand

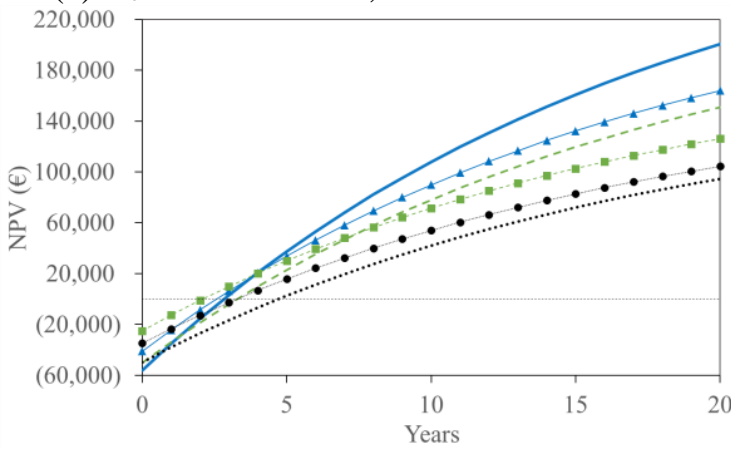

(e) $C_{\text {el }}=0.19 € / \mathrm{kWh}, 30 \%$ heat demand

(d) $C_{\text {el }}=0.13 € / \mathrm{kWh}, 50 \%$ heat demand

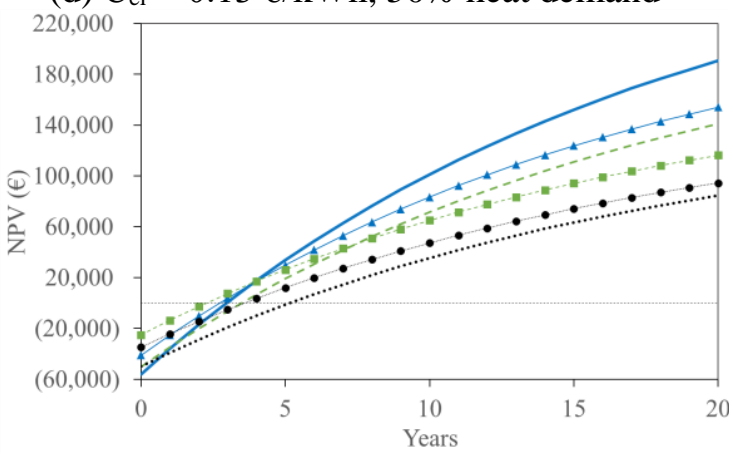

(f) $C_{\text {el }}=0.19 € / \mathrm{kWh}, 50 \%$ heat demand

1035 Figure 15: Variation of NPV over a 20-year plant lifetime for heat demand of 30\% and 50\% of the bottoming ORC engine operating time at a heating cost of $0.03 € / \mathrm{kWh}$, for a range of avoided electricity costs $\left(C_{\mathrm{el}}\right)$ between 0.07 and $0.19 € / \mathrm{kWh}$. Systems with reciprocating-piston, single- and two-stage screw expanders are optimised for maximum net power and minimum specific investment cost in turn.

\section{Conclusions}

The expansion device is one of the most critical components of a cost-effective ORC system for waste heat recovery. This research therefore examines the performance of piston and screw expanders in a small-scale ORC system recovering heat from the exhaust gases of a $185-\mathrm{kW}$ natural-gas reciprocating internal combustion engine in baseload mode. The study expands upon previous work by integrating screw and piston expander models with different working fluids into the optimisation, and by analysing the impact of key parameters such as electricity price and onsite heat demand on project viability. 
1049 The thermodynamic optimisation results show that the correct choice of the working fluid is 1050 fundamental for achieving good performance in each ORC application. Fluids with particularly high cirical temperatures are found to increase the exergy losses at the condenser, while those with low critical temperatures increase the losses in the evaporator. Fluids with intermediate critical temperatures, such as acetone and ethanol, provide optimal results for exhaust gas heat recovery.

For this high-temperature heat source, two-stage screw expanders achieve a higher expansion pressure ratio than single-stage machines without sacrificing efficiency, enabling an improved temperature match, and thus tending to deliver the highest power. The maximum net power output is found to be $17.7 \mathrm{~kW}$, from an ORC engine operating with acetone and a two-stage screw expander. The singlestage piston expander allows a higher expansion ratio than the single-stage screw expander and enables a higher power output for fluids well-suited to the heat-source temperature range.

As the expander is the most expensive component of the ORC system, thermoeconomic optimisation generally leads to increases in both the condensing and evaporating pressures in order to reduce the volumetric flow rate and hence the cost. In most cases, the increase in the power output from using a two-stage screw expander rather than a single-stage screw is sufficient to outweigh the greater investment cost, leading to lower specific investment costs

For most of the fluids considered here, the piston expander is associated with the lowest specific investment cost. The minimum specific investment cost of $1630 € / \mathrm{kW}$ is observed for an ORC engine with a piston expander, using acetone as the working fluid. Since piston expanders are not as mature as screw machines, especially at these scales, this motivates further consideration of this component.

Finally, financial appraisals of the ORC investment show payback periods as low as $2-4$ years when the value of the electricity produced is above $0.13 € / \mathrm{kWh}$, roughly equal to those expected in stationary cogenerating ICE projects. The highest internal rate of return is offered by an ORC system optimised for minimum specific cost with a piston expander. An ORC engine optimised for maximum power with a two-stage screw expander gives the highest net present value, which is appropriate when the electricity value is high enough to reward the increased conversion efficiency of this more expensive technical solution. The influence of the onsite heating demand is also explored, as the adoption of a standard ORC system reduces the availability of such heat for other uses, and the investment profitability is consequently reduced.

The work presented herein outlines a design approach that is more generally applicable to a wide range of small-scale ORC systems. Integrating the expander performance into the optimisation alongside the working fluid selection ensures that the expansion device in the chosen design is feasible and performs well, while also guiding the correct choice of device for maximum project returns. The thermoeconomic optimisation and sensitivity analyses quantify the key factors influencing the profitability of ORC systems for gas-fired ICEs, which are useful for energy operators aiming at maximising the energy performance of specific industrial processes and policymakers looking to propose effective support mechanisms for energy efficiency.

\section{Acknowledgements}

This work was supported by the UK Engineering and Physical Sciences Research Council (EPSRC) [grant number EP/P004709/1]. A short version of this paper was presented at the $4^{\text {th }}$ Annual Engine ORC Consortium (EORCC) Workshop for the Automotive and Stationary Industries, 15-17 November 2017, Detroit. This paper is a substantial extension of the short version of the conference paper. Data supporting this publication can be obtained on request from cep-lab@imperial.ac.uk. 


\section{References}

[1] Amirante R, Cassone E, Distaso E, Tamburrano P. Overview on recent developments in energy storage: Mechanical, electrochemical and hydrogen technologies. Energy Convers Manag 2017;132:372-87.

[2] Markides CN. The role of pumped and waste heat technologies in a high-efficiency sustainable energy future for the UK. Appl Therm Eng 2013;53:197-209. doi:10.1016/j.applthermaleng.2012.02.037.

1104

[3] Tartière T, Astolfi M. A world overview of the organic Rankine cycle market. Energy Procedia 2017;129:2-9.

[4] Pantaleo AM, Camporeale SM, Shah N. Thermo-economic assessment of externally fired micro-gas turbine fired by natural gas and biomass: Applications in Italy. Energy Convers Manag 2013;75:202-13. Pantaleo AM, Giarola S, Bauen A, Shah N. Integration of biomass into urban energy systems for heat and power. Part II: Sensitivity assessment of main techno-economic factors. Energy Convers Manag 2014;83:362-76. small scale combined cycle for energy generation from carbon neutral biomass. Energy Procedia 2017;129:891-8. doi:10.1016/j.egypro.2017.09.213.

Camporeale SM, Ciliberti PD, Fortunato B, Torresi M, Pantaleo AM. Externally fired micro gas turbine and ORC bottoming cycle: optimal biomass/natural gas CHP configuration for residential energy demand. ASME Turbo Expo 2015 Turbine Tech. Conf. Expo., 2015.

[8] Amirante R, De Palma P, Distaso E, Tamburrano P. Thermodynamic analysis of small-scale externally fired gas turbines and combined cycles using turbo-compound components for energy generation from solid biomass. Energy Convers Manag 2018;166. doi:10.1016/j.enconman.2018.04.055.

[9] Pantaleo AM, Camporeale SM, Miliozzi A, Russo V, Shah N, Markides CN. Novel hybrid CSPbiomass CHP for flexible generation: Thermo-economic analysis and profitability assessment. Appl Energy 2017;204:994-1006.

[10] Pantaleo AM, Camporeale SM, Sorrentino A, Miliozzi A, Shah N, Markides CN. Hybrid solarbiomass combined Brayton/organic Rankine-cycle plants integrated with thermal storage: Technoeconomic feasibility in selected Mediterranean areas. Renew Energy 2018.

doi:10.1016/j.renene.2018.08.022.

[11] Quoilin S, Declaye S, Tchanche BF, Lemort V. Thermo-economic optimization of waste heat recovery Organic Rankine Cycles. Appl Therm Eng 2011;31:2885-93. doi:10.1016/j.applthermaleng.2011.05.014.

[12] Chang J-C, Hung T-C, He Y-L, Zhang W. Experimental study on low-temperature organic Rankine cycle utilizing scroll type expander. Appl Energy 2015;155:150-9.

[13] Li T, Zhang Z, Lu J, Yang J, Hu Y. Two-stage evaporation strategy to improve system performance for organic Rankine cycle. Appl Energy 2015;150:323-34.

[14] Benato A, Macor A. Biogas engine waste heat recovery using organic Rankine cycle. Energies 2017;10:1-18. doi:10.3390/en10030327.

[15] Chatzopoulou MA, Markides CN. Thermodynamic optimisation of a high-electrical efficiency integrated internal combustion engine - Organic Rankine cycle combined heat and power system. Appl Energy 2018;226:1229-51. doi:10.1016/j.apenergy.2018.06.022.

[16] Imran M, Usman M, Park B-S, Lee D-H. Volumetric expanders for low grade heat and waste heat recovery applications. Renew Sustain Energy Rev 2016;57:1090-109. doi:10.1016/j.rser.2015.12.139.

[17] Hsu S-W, Chiang H-W, Yen C-W, Hsu S-W, Chiang H-WD, Yen C-W. Experimental investigation of the performance of a hermetic screw-expander organic Rankine cycle. Energies 2014;7:6172-85. doi:10.3390/en7096172.

[18] Dumont O, Parthoens A, Dickes R, Lemort V. Experimental investigation and optimal performance assessment of four volumetric expanders (scroll, screw, piston and roots) tested in a small-scale organic Rankine cycle system. Energy 2018. doi:10.1016/j.energy.2018.06.182.

[19] Qiu G, Liu H, Riffat S. Expanders for micro-CHP systems with organic Rankine cycle. Appl Therm Eng 2011;31:3301-7.

[20] Bao J, Zhao L. A review of working fluid and expander selections for organic Rankine cycle. Renew Sustain Energy Rev 2013;24:325-42. doi:10.1016/j.rser.2013.03.040.

[21] Saghlatoun S, Zhuge W, Zhang Y. Review of expander selection for small-scale organic Rankine 
cycle. ASME 4th Jt. US-European Fluids Eng. Div. Summer Meet. collocated with ASME 12th Int. Conf. Nanochannels, Microchannels, Minichannels, 2014.

[22] Weiß AP. Volumetric expander versus turbine--which is the better choice for small ORC plants. 3rd Int. Semin. ORC Power Syst., 2015, p. 12-4.

[23] Song P, Wei M, Shi L, Danish SN, Ma C. A review of scroll expanders for organic Rankine cycle systems. Appl Therm Eng 2015;75:54-64.

[24] Ziviani D, Gusev S, Lecompte S, Groll EA, Braun JE, Horton WT, et al. Characterizing the performance of a single-screw expander in a small-scale organic Rankine cycle for waste heat recovery. Appl Energy 2016;181:155-70. doi:10.1016/j.apenergy.2016.08.048.

[25] Glavatskaya Y, Podevin P, Lemort V, Shonda O, Descombes G. Reciprocating expander for an exhaust heat recovery Rankine cycle for a passenger car application. Energies 2012;5:1751-65. doi:10.3390/en5061751.

[26] Taleb AI, Sapin P, Barfuß C, Fabris D, Markides CN. CFD analysis of thermally induced thermodynamic losses in the reciprocating compression and expansion of real gases. Int Semin NonIdeal Compressible-Fluid Dyn Propuls Power 2017;821. doi:10.1088/1742-6596/755/1/011001.

[27] Oyewunmi OA, Kirmse CJW, Pantaleo AM, Markides CN. Performance of working-fluid mixtures in ORC-CHP systems for different heat-demand segments and heat-recovery temperature levels. Energy Convers Manag 2017;148:1508-24. doi:10.1016/j.enconman.2017.05.078.

[28] White MT, Oyewunmi OA, Haslam AJ, Markides CN. Industrial waste-heat recovery through integrated computer-aided working-fluid and ORC system optimisation using SAFT- $\gamma$ Mie. Energy Convers Manag 2017;150:851-69.

[29] White MT, Oyewunmi OA, Chatzopoulou MA, Pantaleo AM, Haslam AJ, Markides CN. Computer-aided working-fluid design, thermodynamic optimisation and thermoeconomic assessment of ORC systems for waste-heat recovery. Energy 2018;161:1181-98.

[30] Astolfi M. Techno-economic optimization of low temperature CSP systems based on ORC with screw expanders. Energy Procedia 2015;69:1100-12. doi:10.1016/j.egypro.2015.03.220.

[31] Sapin P, Simpson M, White AJ, Markides CN. Lumped dynamic analysis and design of a highperformance reciprocating-piston expander. 30th Int. Conf. Effic. Cost, Optim. Simul. Environ. Impact Energy Syst. ECOS 2017, 2017.

[32] Lemmon EW, Huber ML, McLinden MO. NIST Standard Reference Database 23: Reference Fluid Thermodynamic and Transport Properties-REFPROP, Version 9.1, National Institute of Standards and Technology, Standard Reference Data Program, Gaithersburg 2013.

[33] Shu G, Li X, Tian H, Liang X, Wei H, Wang X. Alkanes as working fluids for high-temperature exhaust heat recovery of diesel engine using organic Rankine cycle. Appl Energy 2014;119:204-17.

[34] Chatzopoulou MA, Simpson M, Sapin P, Markides CN. Off-design optimisation of organic Rankine cycle (ORC) engines with piston expanders for medium-scale combined heat and power applications. Appl Energy 2019;238:1211-36. doi:10.1016/j.apenergy.2018.12.086.

[35] Simpson MC, Pantaleo AM, De Palma P, Markides CN. Design and thermo-economic optimisation of small-scale bottoming ORC systems coupled to biomass CHP gasification cycles. Int. Conf. Effic. Cost, Optimisation, Simul. Environ. Impact Energy Syst., Guimarães, Portugal: 2018.

[36] Lê V, Kheiri A, Feidt M, Pelloux-Prayer S. Thermodynamic and economic optimizations of a waste heat to power plant driven by a subcritical ORC (organic Rankine cycle) using pure or zeotropic working fluid. Energy 2014;78:622-38.

[37] Edwards JE. Design and rating shell and tube heat exchangers. P I Des Ltd, Teesside 2008.

[38] Jung DS, Mclinden M, Radermachert R, Didion D. Horizontal flow boiling heat transfer experiments with a mixture of R22 / R114. Int J Heat Mass Transf 1989;32:131-45.

[39] Shin JY, Kim MS, Ro ST. Correlation of evaporative heat transfer coefficients for refrigerant mixtures. Int Refrig Air Cond Conf 1996:151-6.

[40] Oyewunmi O, Markides C. Thermo-economic and heat transfer optimization of working-fluid mixtures in a low-temperature organic Rankine cycle system. Energies 2016;9:448. doi:10.3390/en9060448.

[41] Perry JH. Chemical Engineers' Handbook 1950.

[42] Seider WD, Seader JD, Lewin DR, Widagdo S. Product and Process Design Principles: Synthesis, Analysis, and Design, Section 9.32008.

[43] Loh HP, Lyons J, White C. W. Process Equipment Cost Estimation: Final Report. Natl Energy 
Technol Center, DOE/NETL-2002/1169 2002.

[44] Bitzer. Price List 2015. 2015.

[45] Panesar AS, Morgan RE, Miché NDD, Heikal MR. Working fluid selection for a subcritical bottoming cycle applied to a high exhaust gas recirculation engine. Energy 2013;60:388-400.

[46] Bird, R. H., Hribar, M. E. Nocedal J. An interior point algorithm for large-scale nonlinear programming. SIAM J Optim 1999;9:877-900.

[47] Oyewunmi OA, Lecompte S, De Paepe M, Markides CN. Thermoeconomic analysis of recuperative sub- and transcritical organic Rankine cycle systems. Energy Procedia 2017;129:5865. doi:10.1016/j.egypro.2017.09.187.

[48] Pantaleo AM, Camporeale S, Shah N. Natural gas-biomass dual fuelled microturbines: Comparison of operating strategies in the Italian residential sector. Appl Therm Eng 2014;71:686-96.

[49] Tocci L, Pal T, Pesmazoglou I, Franchetti B. Small scale organic Rankine cycle (ORC): A technoeconomic review. Energies 2017;10:413.

[50] Mainali B, Silveira S. Alternative pathways for providing access to electricity in developing countries. Renew Energy 2013;57:299-310. doi:10.1016/j.renene.2013.01.057.

[51] Pantaleo AM, Camporeale S, Fortunato B. Small scale biomass CHP: Techno-economic performance of steam vs gas turbines with bottoming ORC. Energy Procedia 2015;82:825-32. 